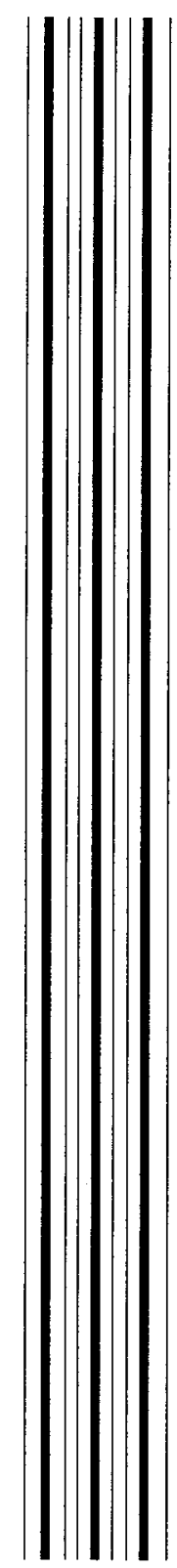

UCRL-ID-138931

\title{
NIF Spot Summary
}

\author{
P. E. Young
}

April 13, 2000

U.S. Department of Energy

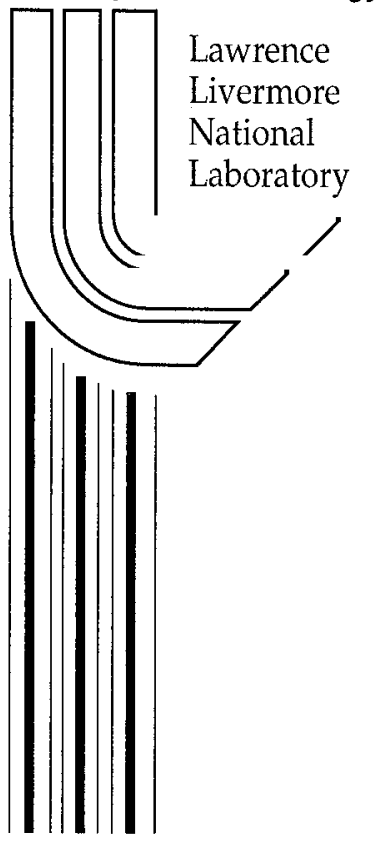




\section{DISCLAIMER}

This document was prepared as an account of work sponsored by an agency of the United States Government. Neither the United States Government nor the University of California nor any of their employees, makes any warranty, express or implied, or assumes any legal liability or responsibility for the accuracy, completeness, or usefulness of any information, apparatus, product, or process disclosed, or represents that its use would not infringe privately owned rights. Reference herein to any specific commercial product, process, or service by trade name, trademark, manufacturer, or otherwise, does not necessarily constitute or imply its endorsement, recommendation, or favoring by the United States Government or the University of California. The views and opinions of authors expressed herein do not necessarily state or reflect those of the United States Government or the University of California, and shall not be used for advertising or product endorsement purposes.

Work performed under the auspices of the U. S. Department of Energy by the University of California Lawrence Livermore National Laboratory under Contract W-7405-Eng-48.

This report has been reproduced directly from the best available copy.

Available to DOE and DOE contractors from the Office of Scientific and Technical Information

P.O. Box 62, Oak Ridge, TN 37831

Prices available from (423) 576-8401

http://apollo.osti.gov/bridge/

Available to the public from the National Technical Information Service

U.S. Department of Commerce 5285 Port Royal Rd., Springfield, VA 22161 http:/ / www.ntis.gov/

OR

Lawrence Livermore National Laboratory Technical Information Department's Digital Library http://www.llnl.gov/tid/Library.html 
April 13, 2000

NIF_0046162

To: $\quad$ NIF Mission Support Staff

From: $\quad$ Peter Young

Subject: $\quad$ NIF spot summary

We are compiling a list of anticipated target spot sizes that are specified by the NIF users groups. This data will be used to anticipate demands for phase plates. The spot size also has an impact on the laser operation. Presently the phase plates are designed to sit in the $1 \omega$ section of the FOA (before the conversion crystals). Intensity modulations produced by the phase plates are nonlinearly proportional to the laser spot size. For spot sizes above $3 \mathrm{~mm}$ diameter, the intensity modulations are large enough that the damage threshold for the remainder of the FOA is exceeded. For experiments requiring spot diameters larger than $3 \mathrm{~mm}$, it is suggested that the phase plates sit in the $3 \omega$ section of the FOA. For planning purposes, the cost of the $3 \omega$ phase plates is presently projected to be more than that of a $1 \omega$ phase plate due to the use of inclusion-free fused silica as the substrate material.

Below is a summary of a meeting that we had on February 16, 2000 in order to catalogue the possible range of requested NIF spot sizes. Copies of the viewgraphs which were presented will be attached to this.

\section{Ignition hohlraums (Pollaine/Suter)}

Hohlraum optimization strategies put an upper bound on the spot sizes of $1-2 \mathrm{~mm}$ high $\mathrm{x} 2 \mathrm{~mm}$ wide

Scale 1 point design:

$\begin{array}{llc}\underline{\text { Angle }} & \underline{\varepsilon} & \text { Size }, \mathrm{mm} \\ 23.5^{\circ} & 1.12 & 0.67 \times 0.75 \\ 30.0^{\circ} & 1.21 & 0.64 \times 0.78 \\ 44.5^{\circ} & 1.59 & 0.56 \times 0.89 \\ 50.0^{\circ} & 1.88 & 0.52 \times 0.97\end{array}$

Scale 1 with large spot to reduce intensity for LPI:
Angle
$\underline{\varepsilon}$
Size. $\mathrm{mm}$
$23.5^{\circ}$
1.12
$1.34 \times 1.50$ 
High Yield spot sizes could use spots $\sim 2 \mathrm{~mm}$

23.5

$2.0 \times 2.2$

50.0

$1.4 \times 2.2$

Planar hydrodynamics experiments (J. Edwards)

Spot diameters up to $6 \mathrm{~mm}$ are envisioned. Illumination uniformity is an issue but needs to be quantified.

Spot diameter (mm)

5.5

4.2

3.6

2.9
Pulse length (ns)

80

38

25

14

\section{NWET experiments (Suter)}

Maximum spot diameter $=2 \mathrm{~mm}, \mathrm{I}_{\text {inner }}=5.3 \times 10^{13} \mathrm{~W} / \mathrm{cm}^{2}, \mathrm{I}_{\text {outer }}=8.3 \times 10^{13} \mathrm{~W} / \mathrm{cm}^{2}$

Pulse length $\approx 6 \mathrm{~ns}$

SSMP (from Josh's FOA chart)

$250-150 \mu \mathrm{m}$ diameter, $500-300 \mathrm{TW}$

HEDS (John Edwards)

A few times the nominal NIF spot size, which makes it $\sim 1.5$ to $2 \mathrm{~mm}$. This needs to be specified more precisely.

Direct Drive (Richard Town, LLE)

$\sim 3 \mathrm{~mm}$ diameter 


\title{
Ignition hohIraums
}

\author{
Steve Pollaine
}


The focal plane intensity profile used in our simulations is the convolution of the kinoform phase plate profile with the profile due to optics imperfections

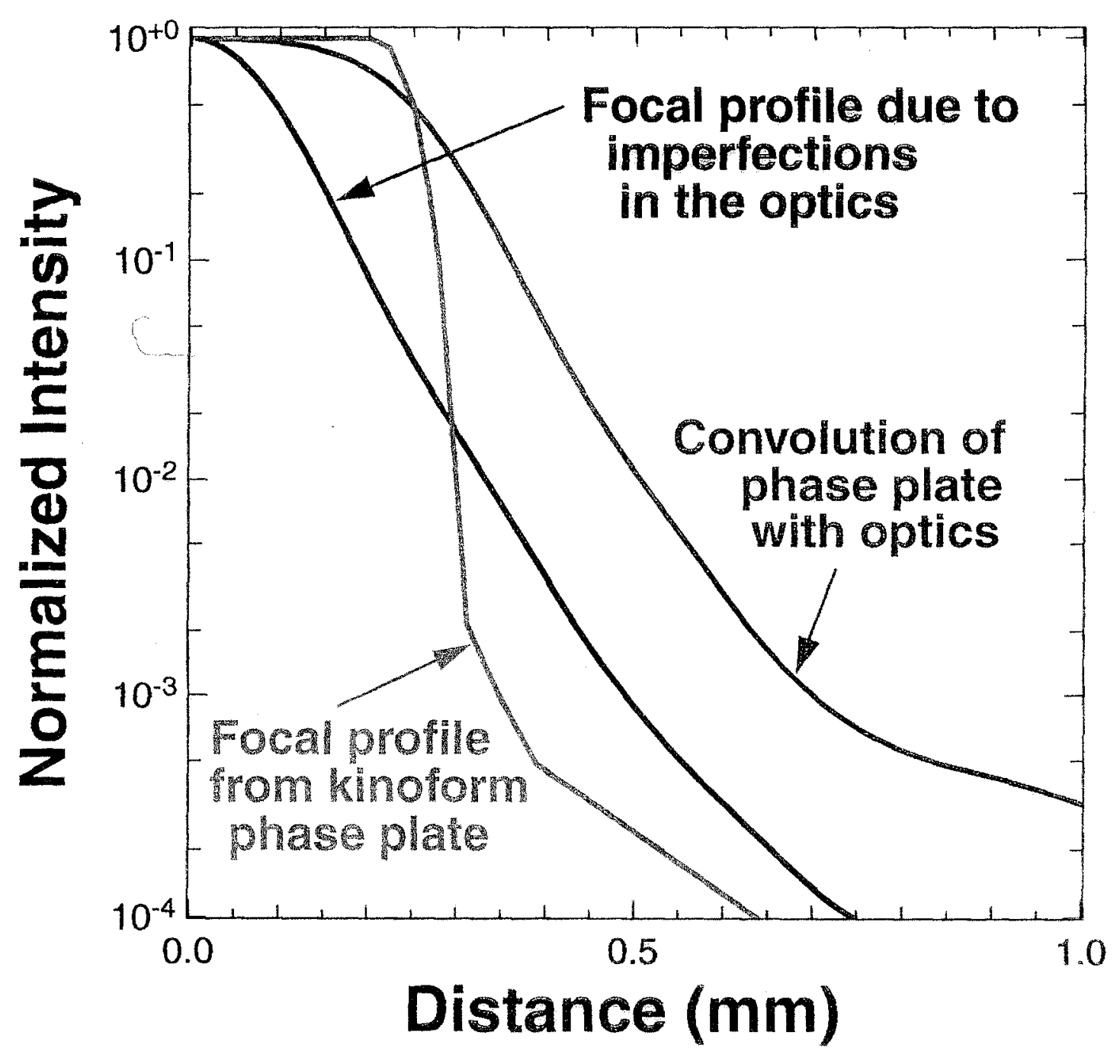


At peak power, most of the hohlraum interior is at one tenth critical density

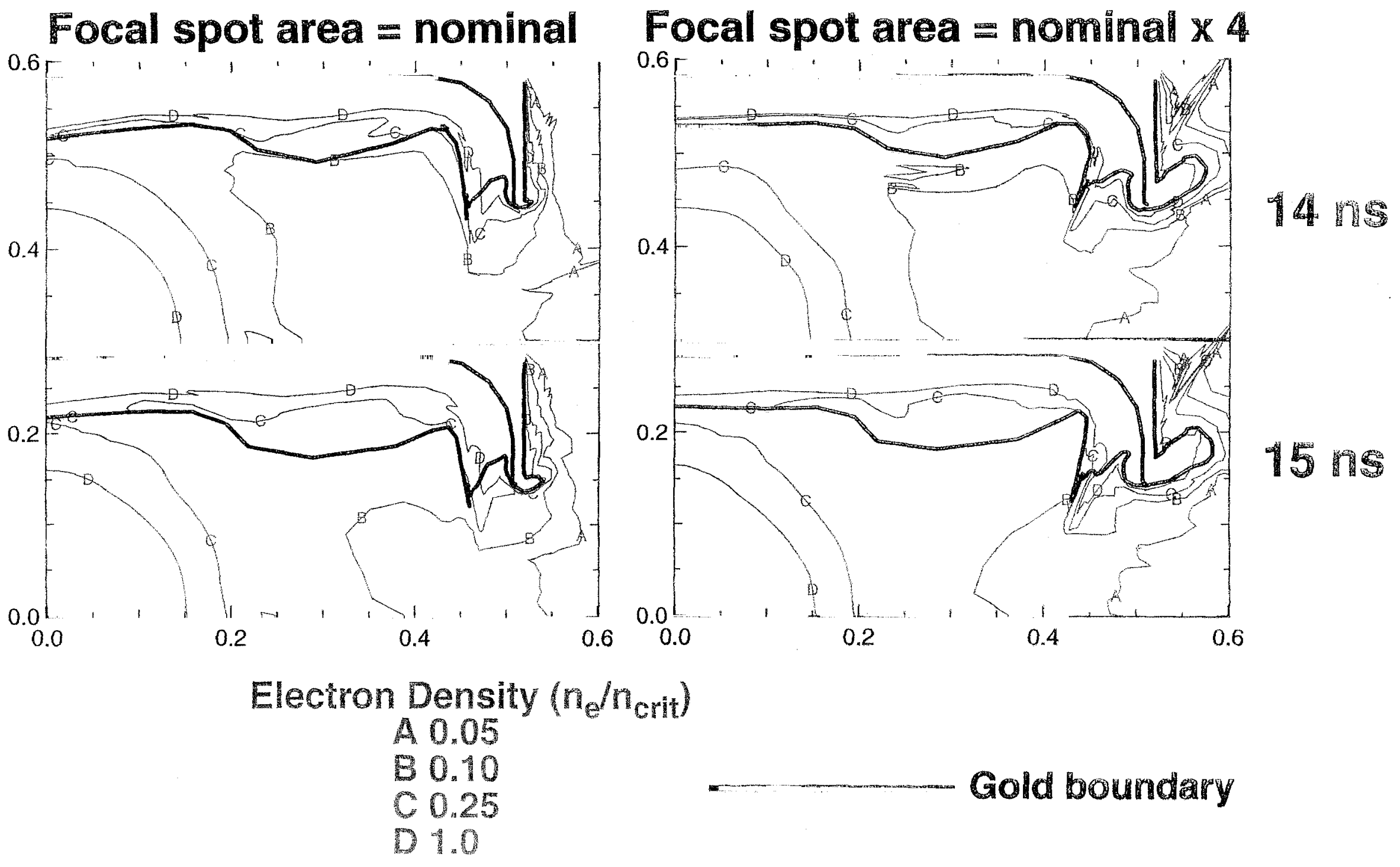


At peak power, most of the hohlraum interior is at 4 $\mathrm{KeV}$
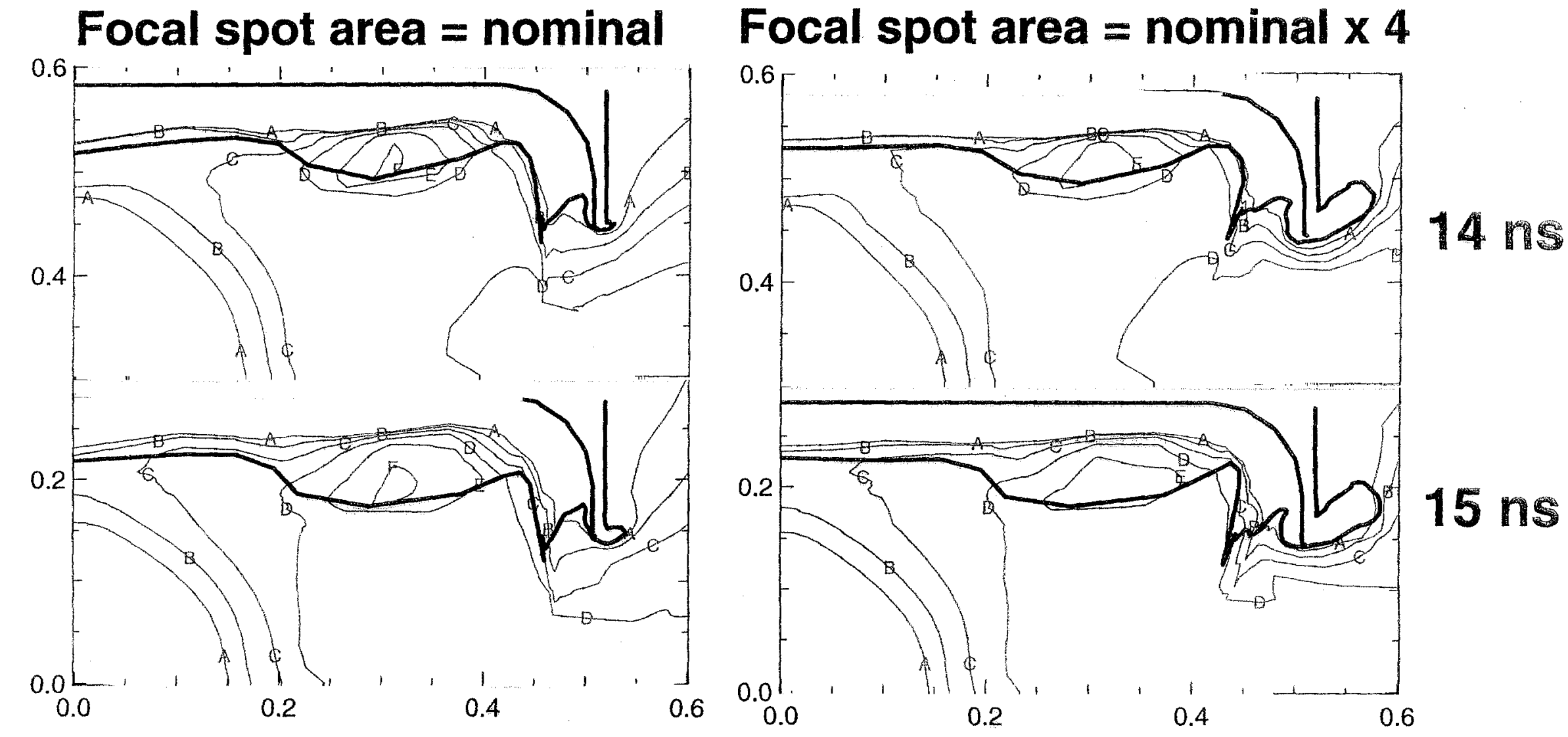

Electron Temperature

A 1

B 2

C 3

Gold boundary

D 4

E 5

F 6 
Decreasing the size of the laser entrance hole reduces the need for laser energy and power

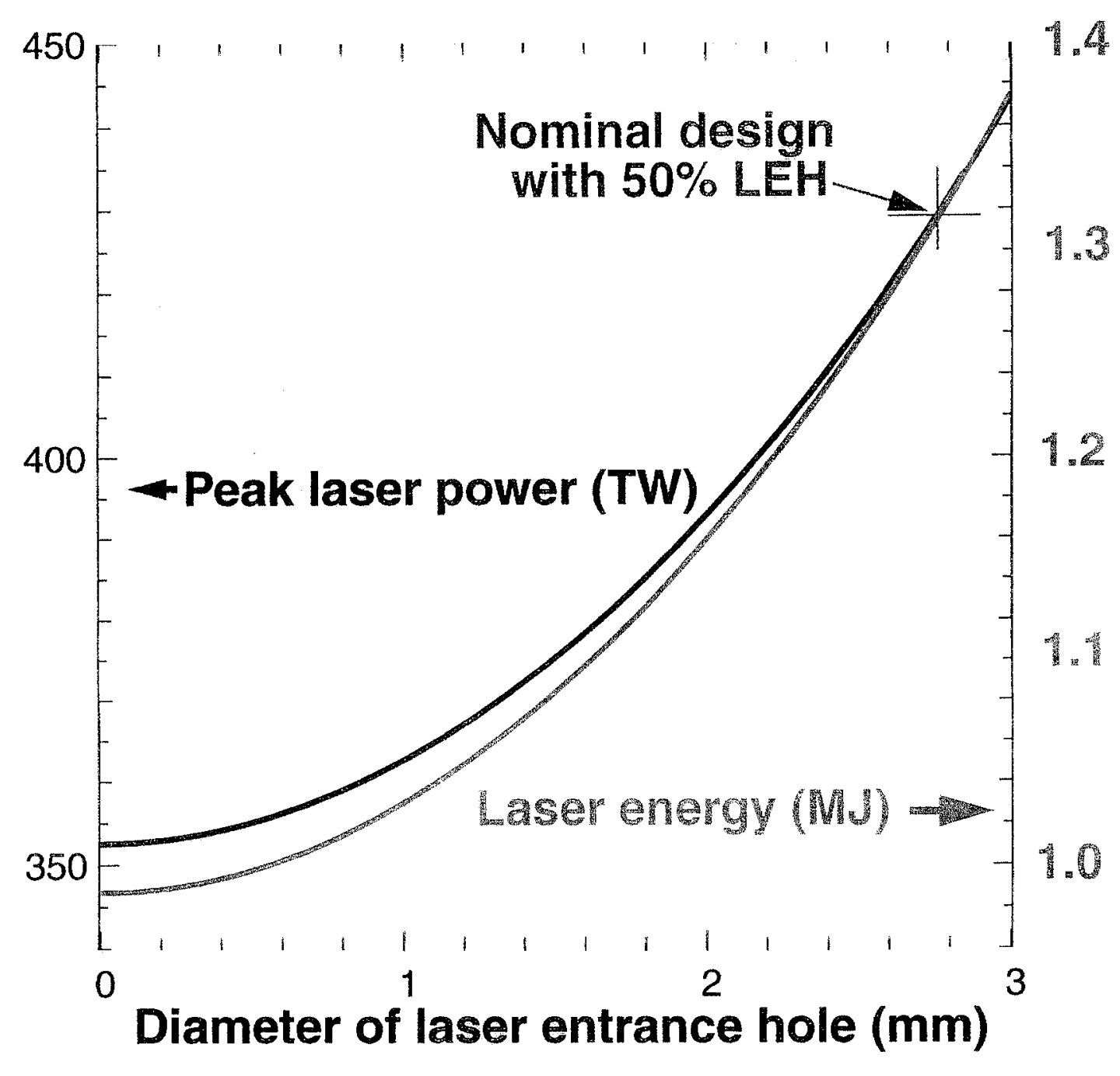


Calculations indicate that considerable margin exists in both inner and outer cones to decrease the central intensity

- without significant increase in plasma absorption

Calculated integrated inverse bremsstrahlung transmission of entire focal beam as a function of beam size (plotted as a function of central peak intensity). Each transmission curve is based on the plasma calculated from a Lasnex run in which the assumed beam size is constant as labeled.

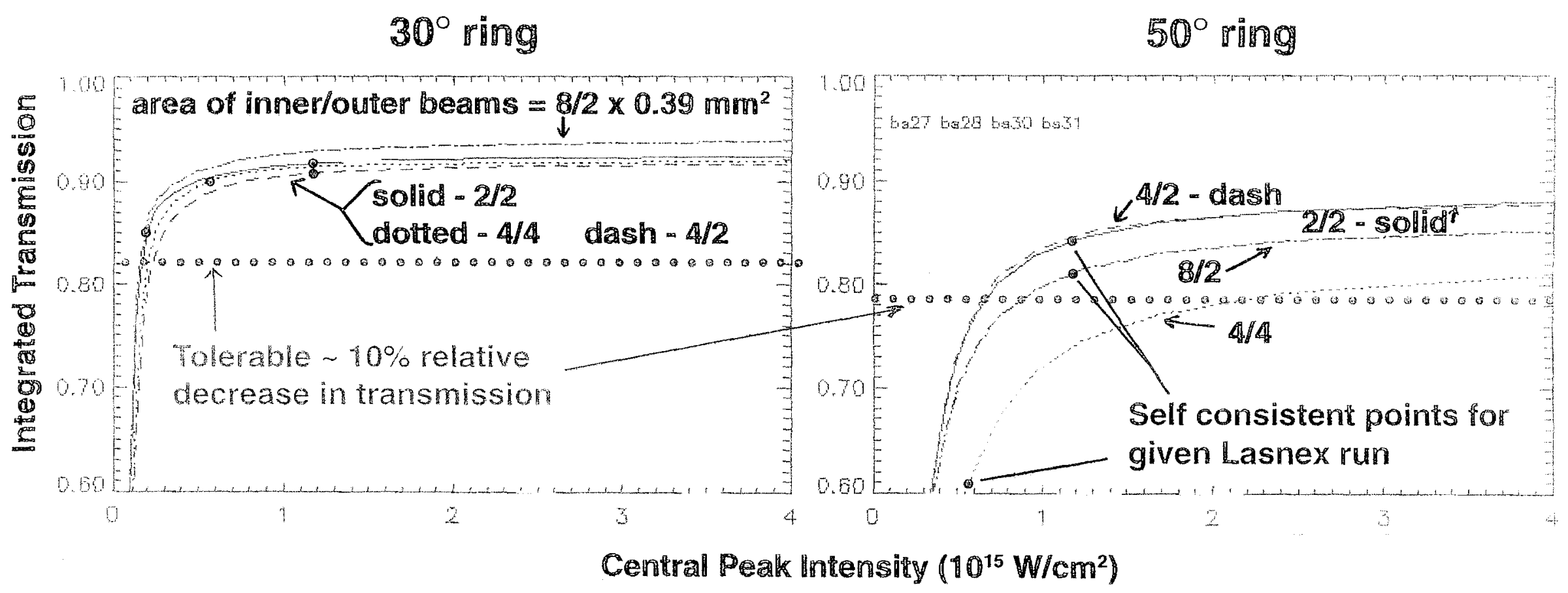

Curves are labeled with the assumed focal beam areas of the inner/outer rings in a given Lasnex calculation as a multiple of the NIF baseline area of $\pi \cdot(0.5 \mathrm{~mm}) \cdot(0.25 \mathrm{~mm})=0.39 \mathrm{~mm}^{2}$ 


\section{In our LASNEX simulations, we minimized absorption by optimizing the eccentricity of each beam cone}

PT hohlraum requires 430 TW

This is $430 / 48=9.0$ TW per quad

For the nominal focal spot size of $0.5 \mathrm{~mm} \times 1.0 \mathrm{~mm}$, the area is $0.39 \mathrm{~mm}^{2}$ and the intensity per quad is

$2.3 \times 10^{15} \mathrm{~W} / \mathrm{cm}^{2}$

Beam cone

angle

$23.5^{\circ}$

$30.0^{\circ}$

$44.5^{\circ}$

$50.0^{\circ}$
Dimensions $(\mathrm{mm})$ with

Eccentricity* same area of $0.39 \mathrm{~mm}^{2}$

1.12

1.21

1.59

1.88
$0.67 \times 0.75$

$0.64 \times 0.78$

$0.56 \times 0.89$

$0.52 \times 0.97$

* As we vary the size of each ellipse, we keep the eccentricity of each focal spot constant 
Total intensity vs radius, move 11.25 (dash)

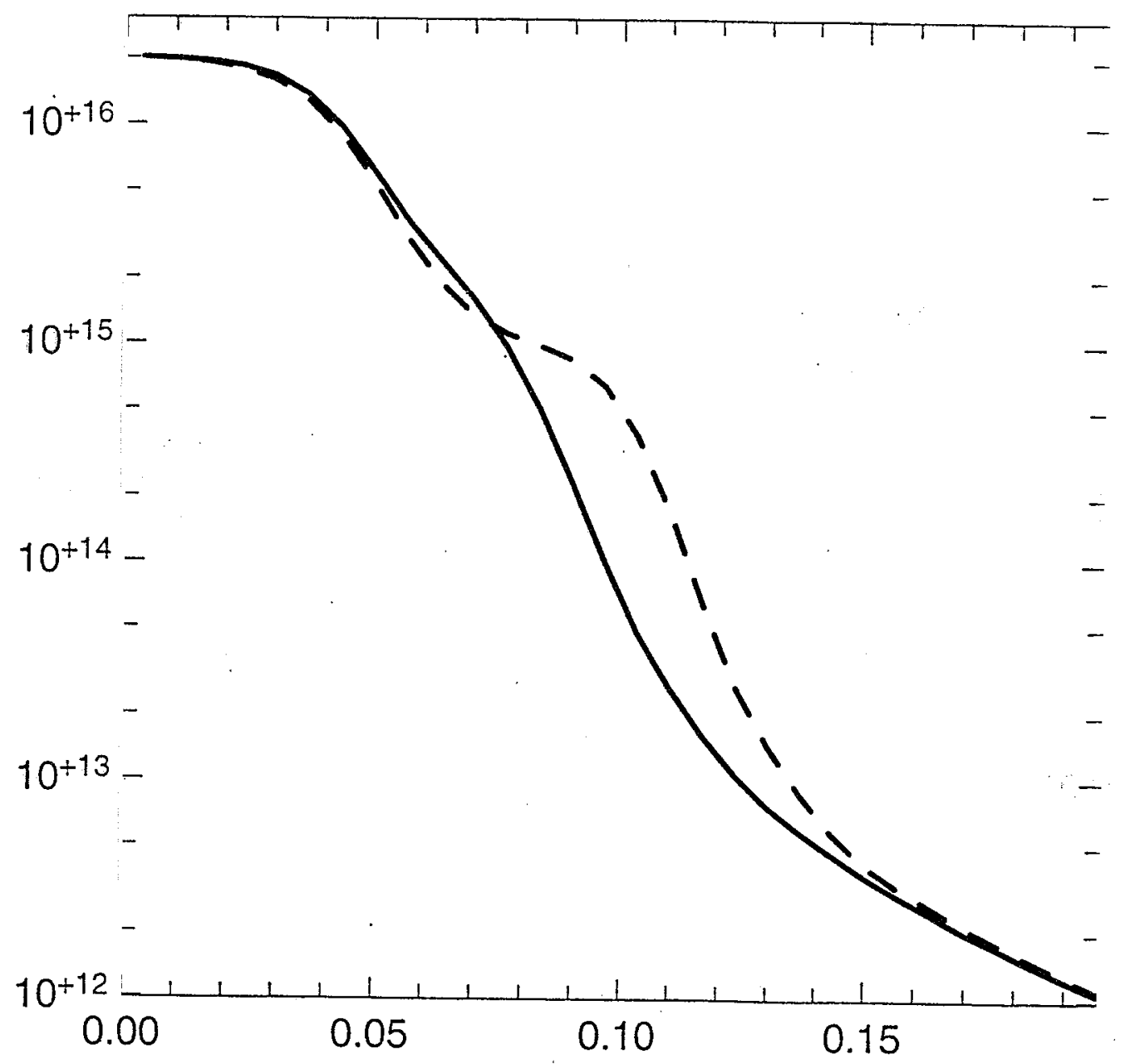

A: plg, it1 $(, 72), y \operatorname{l} \in h(, 72)$

B: plg, itl $(, 24)$, yleh $(, 24)$

C: plg, itla $(, 72), y l \in h(, 72)$

D: plg, itla $(, 24)$, yleh $(, 24)$ 


\section{Total intensity for 0.6 scale}

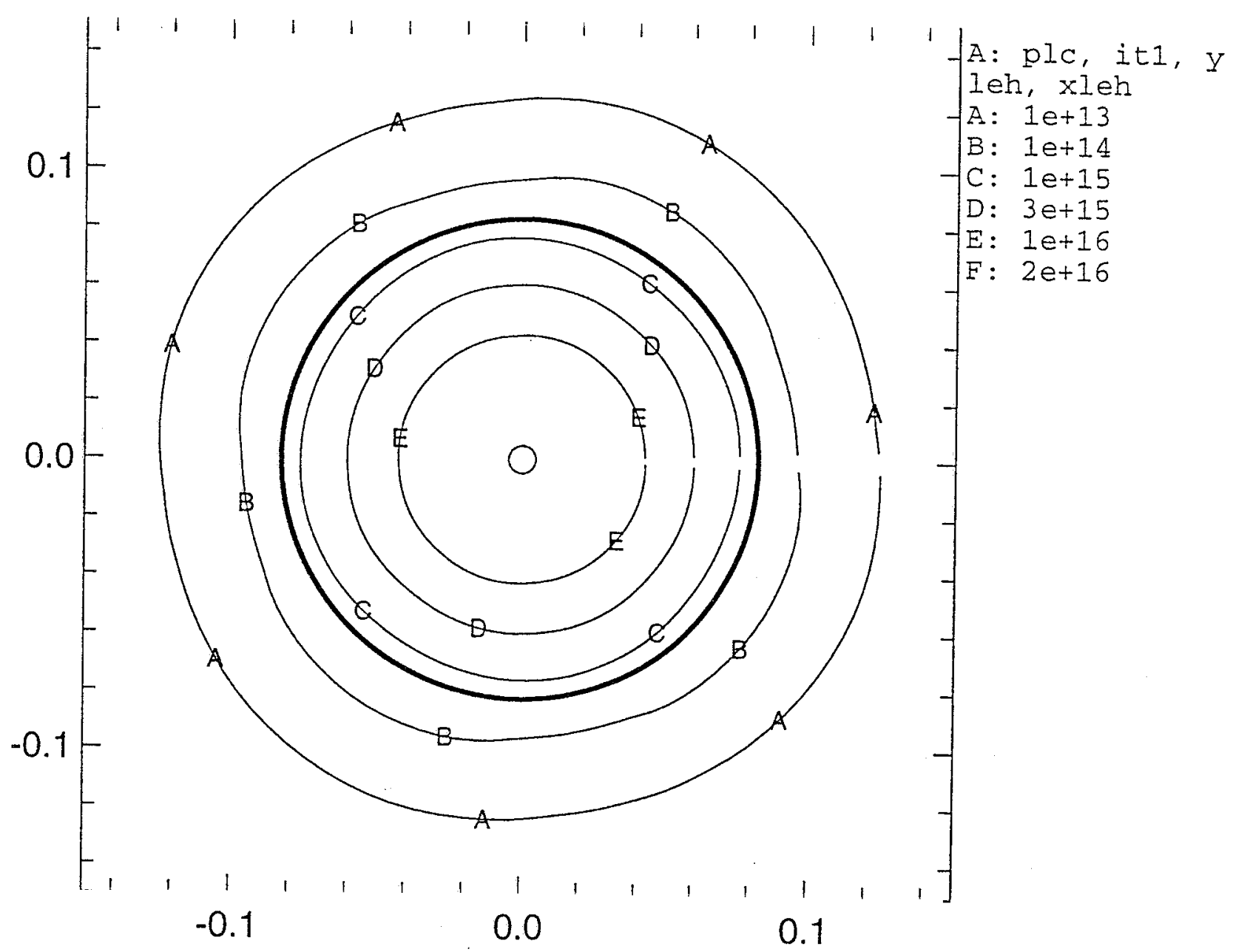

A: plc, it1, yleh, xleh

circle 


\section{Total intensity for 0.6 scale, move 30 beam 11.25 deg}

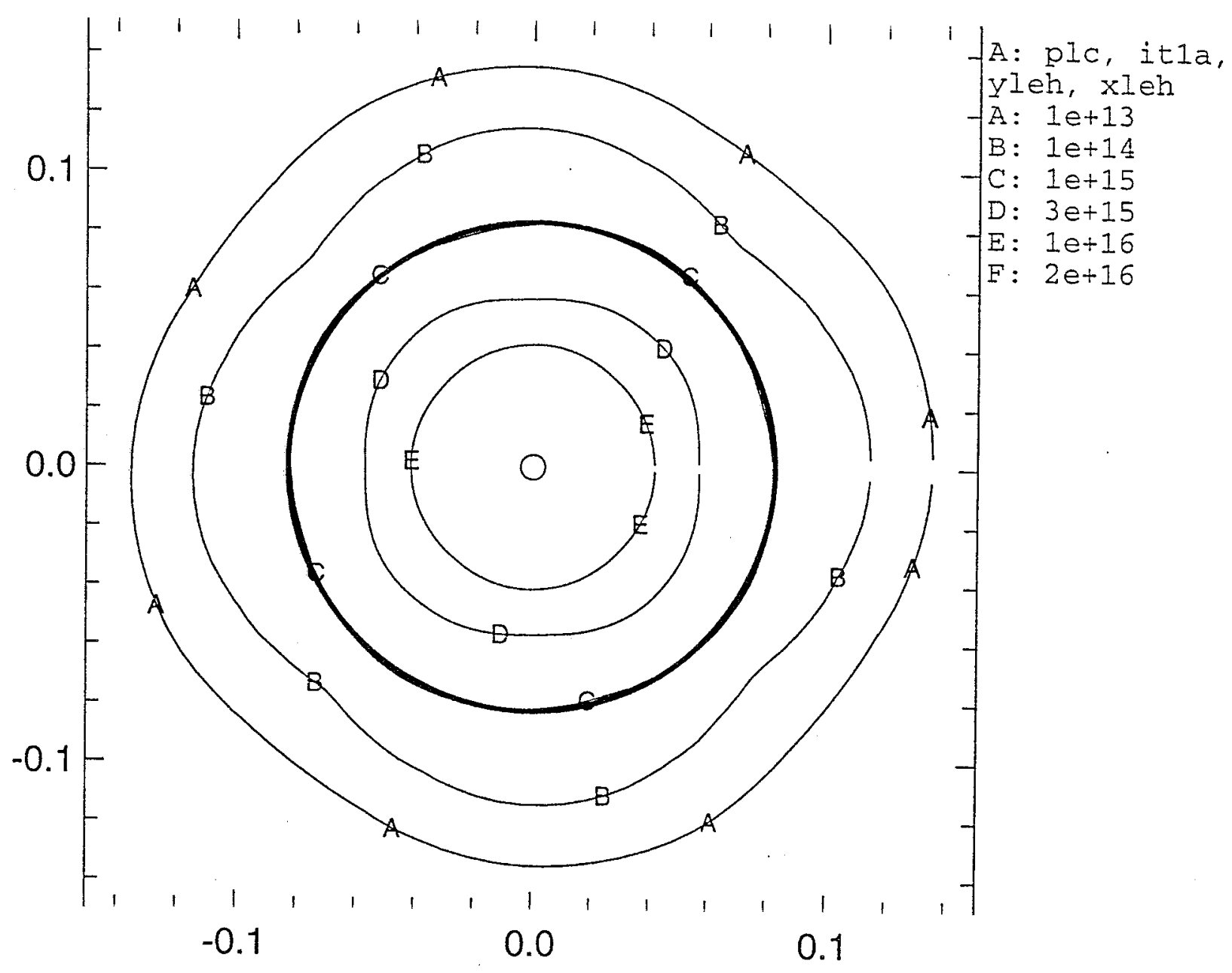

A: plc, itla, yleh, xleh

circle 
Trhf10(solid), 10a-11.25(dash), 10b-11.25+small(dot-dash)

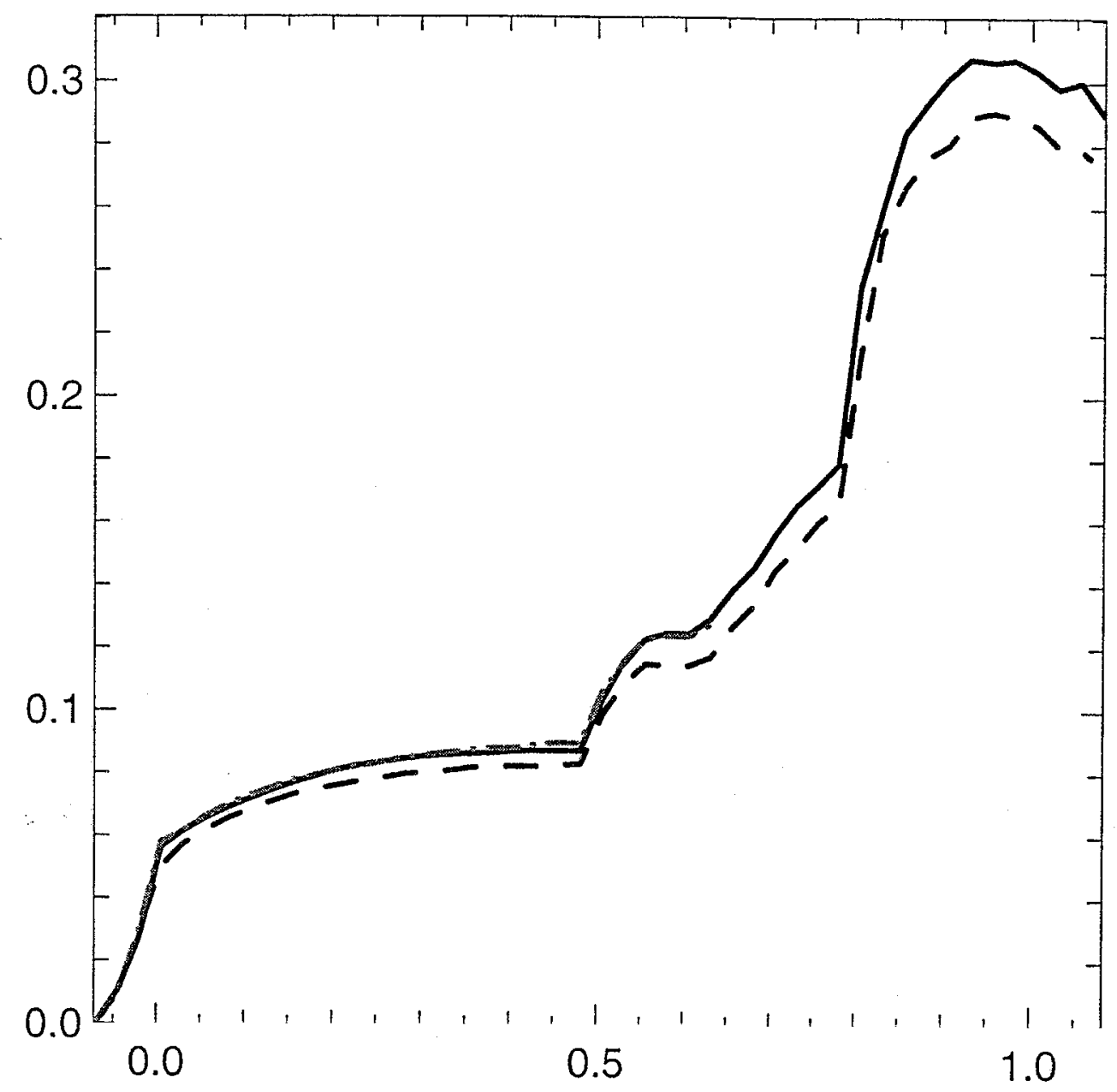

A: plg, f.po^.25, f.times

$B$ : plg, a.po^.25, a.times

C: plg, b.po^.25, b.times 
P2/P0, hf10(solid), 10a-11.25(dash), 10b-11.25+small(dot-dash)

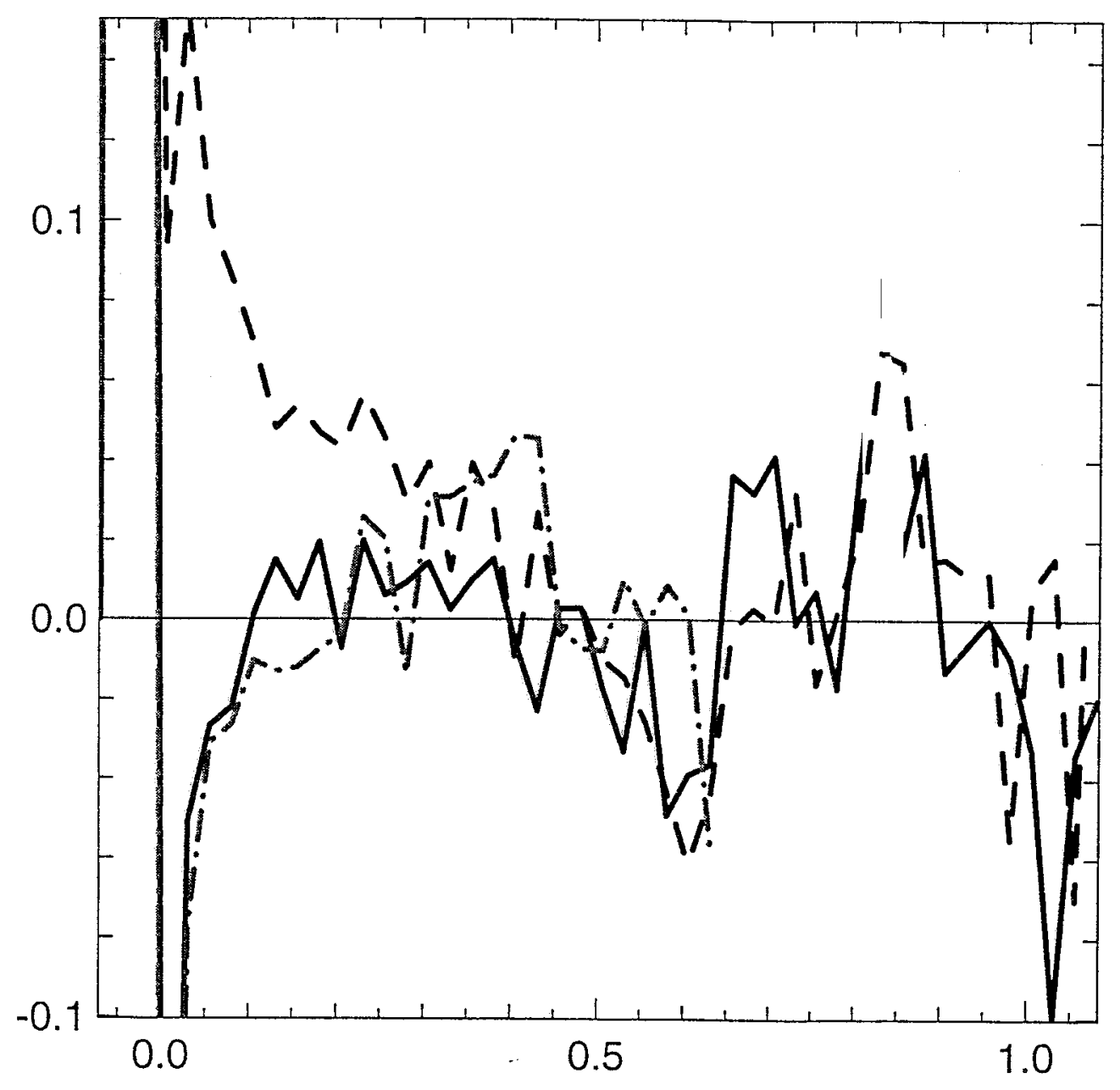
A: plg, f.p2po, f.times
B: plg, a.p2po, a.times
C: plg, b.p2po, b.times 


\section{6 scale 50 deg. beam in LEH}

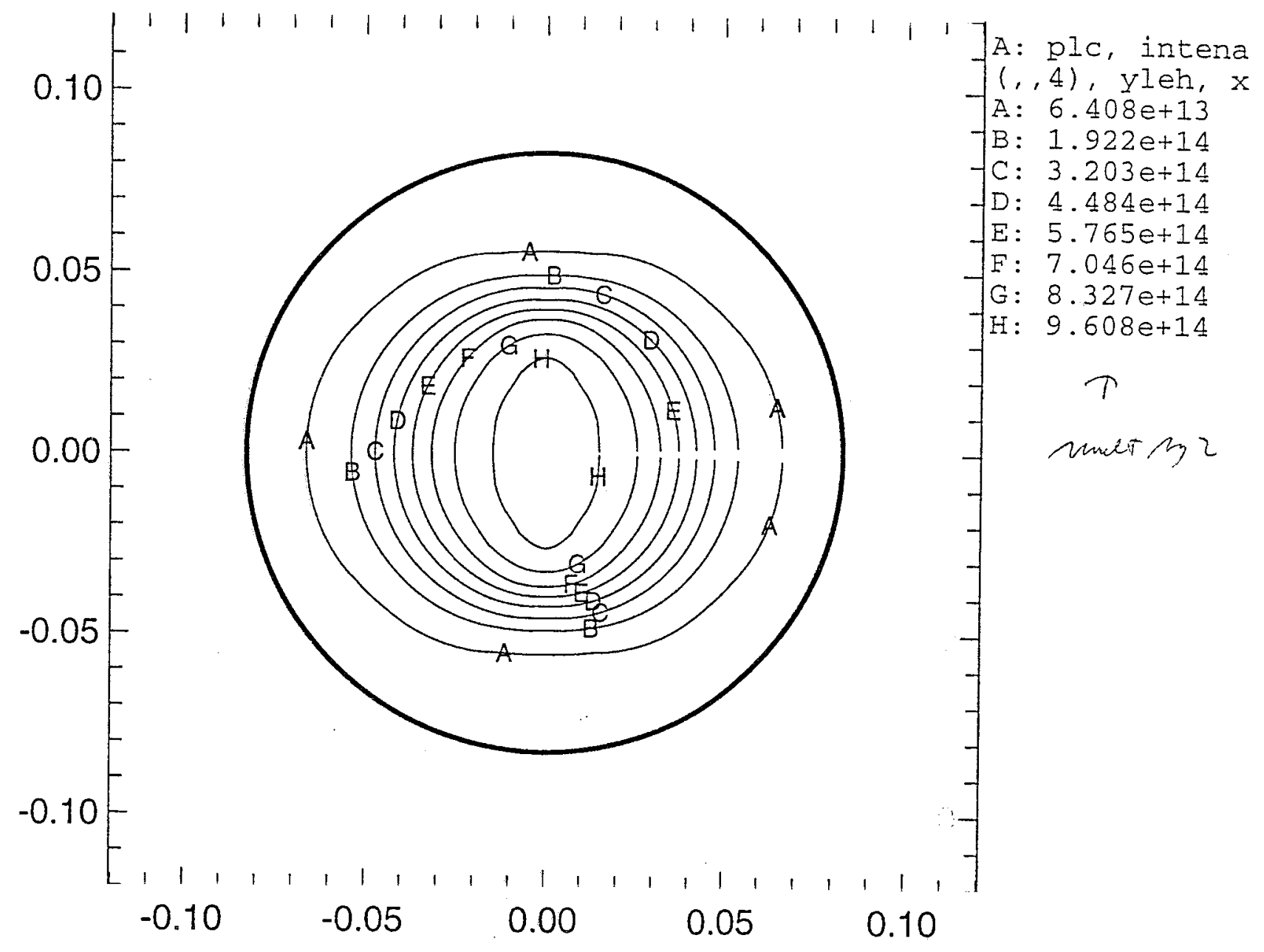

A: plc, intena $(, 4), y l e h, x l e h$ circle 
0.6 scale 30 deg. beam in LEH, moved 11.25 deg

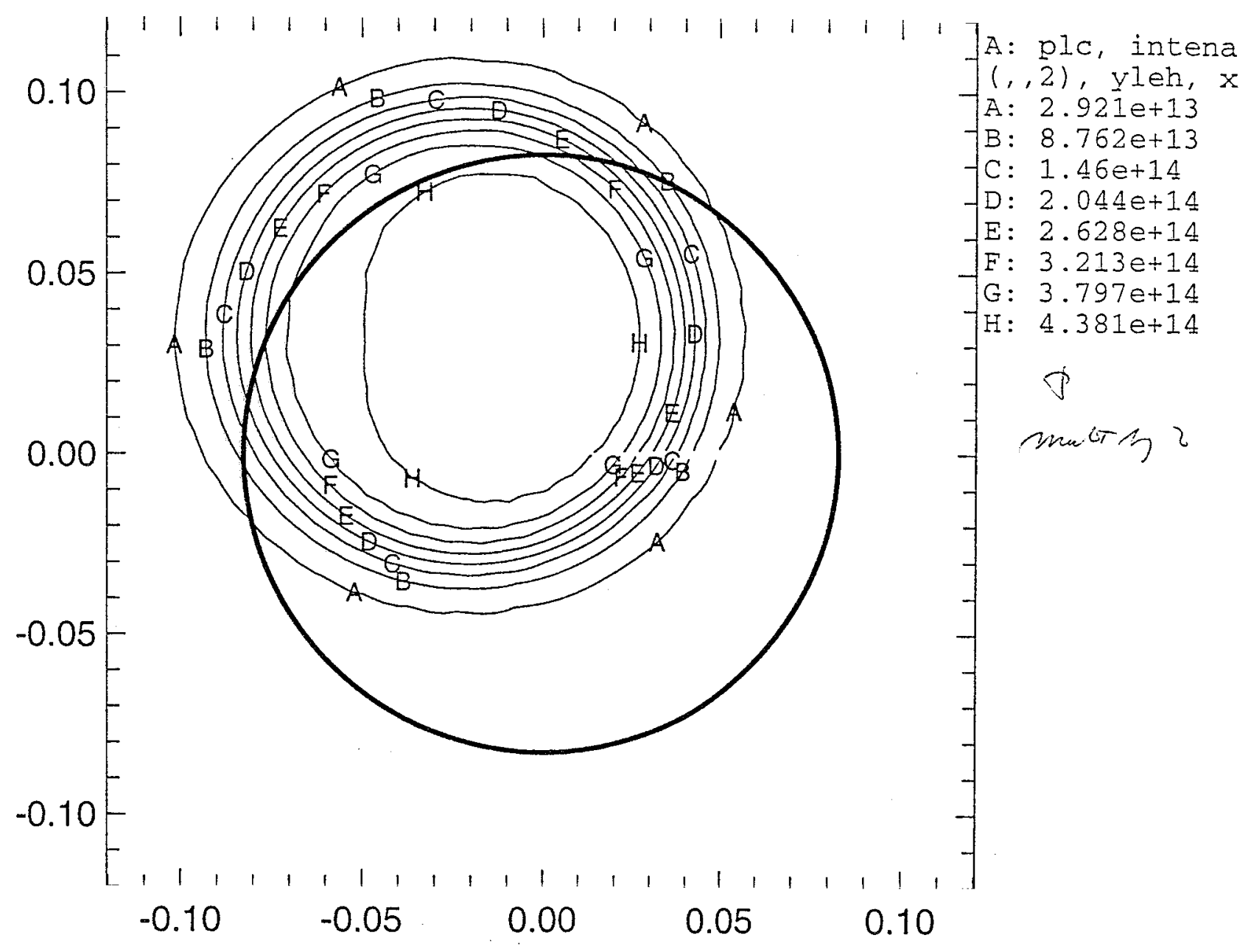

A: plc, intena $(, 2), y l e h, x l e h$ circle 


\section{6 scale 30 deg. beam in LEH}

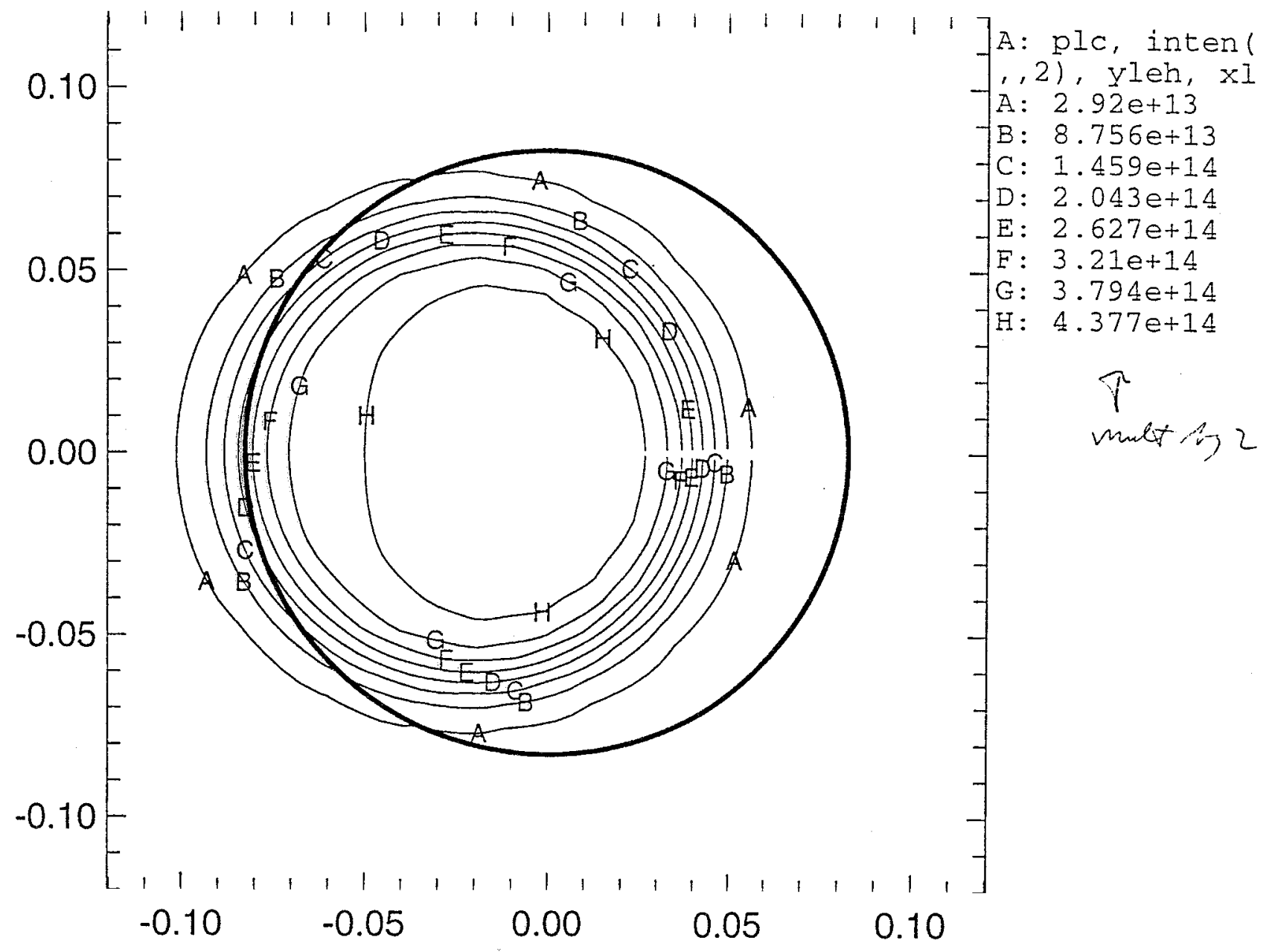

A: plc, inten $(, 2), y l e h, x l e h$ circle 
Total intensity vs radius, full NIF

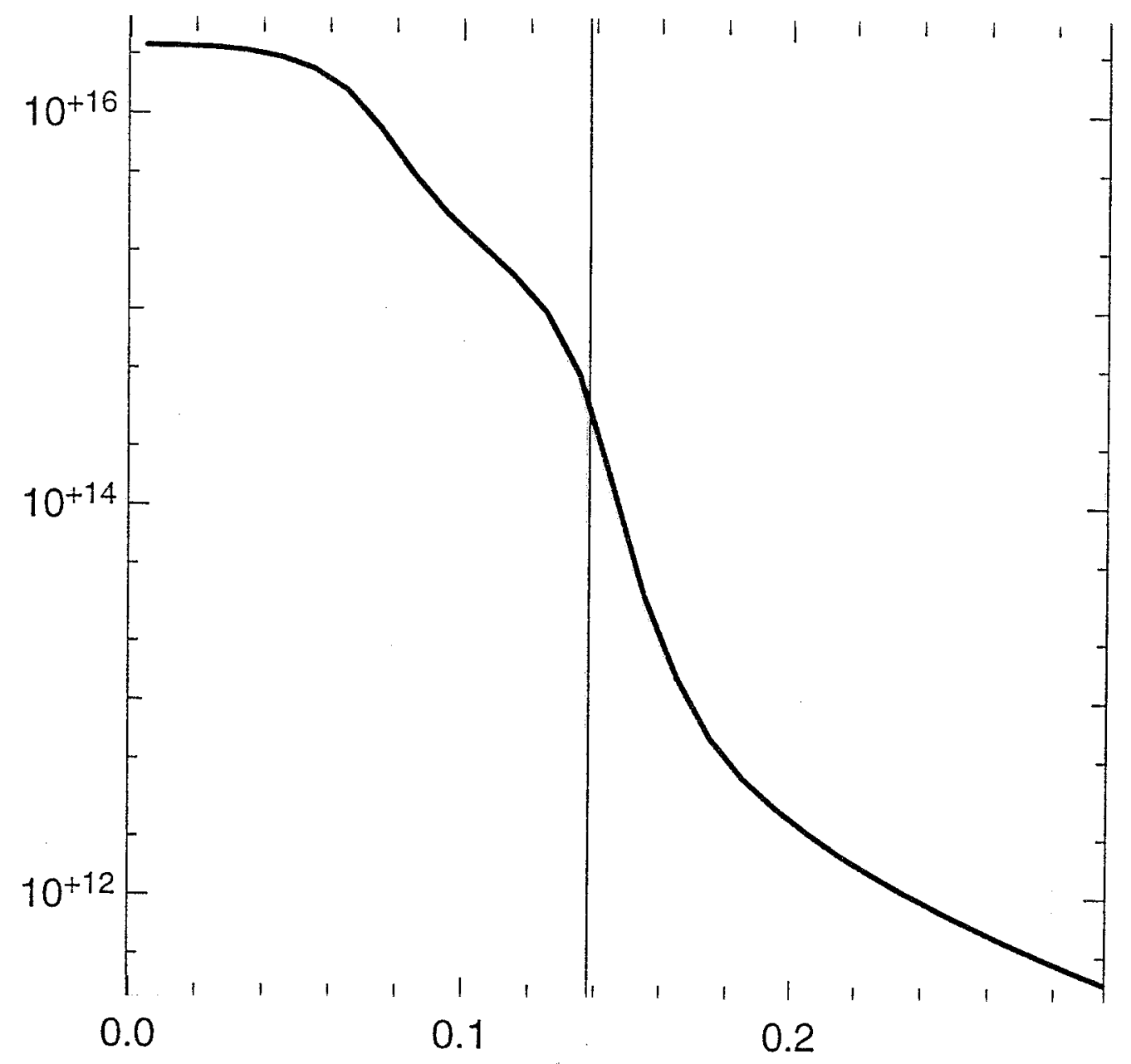

A: plg, itot $(, 24), y l \in h(, 24)$

0.138 


\section{Total intensity vs radius for scale 1 NIF}

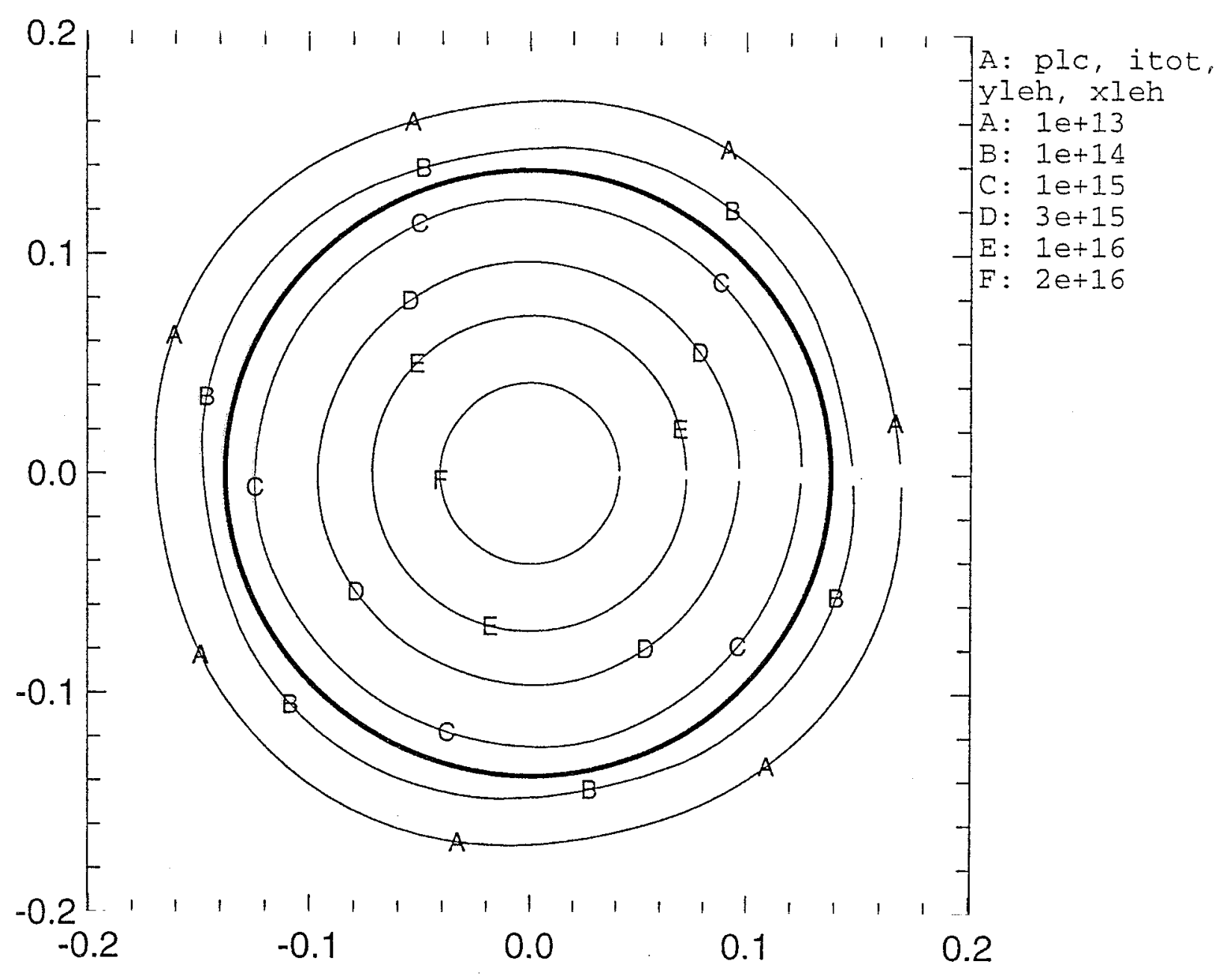

A: plc, itot, yleh, xleh circle 


\section{Standard NIF beams}

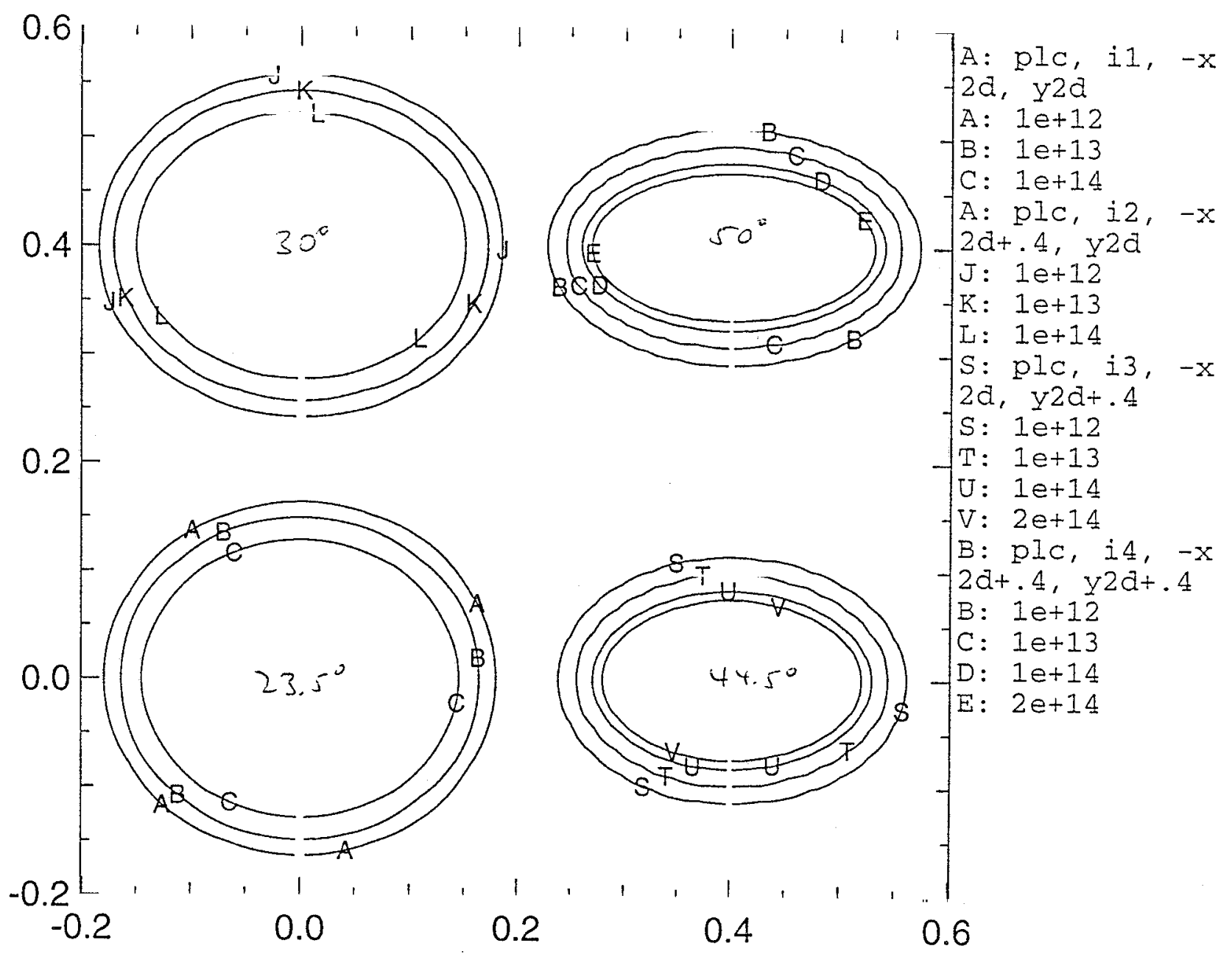

A: plc, il, $-x 2 d, y 2 d$

A: plc, i2, $-x 2 d+.4, y 2 d$

S: plc, i3, $-x 2 d, y^{2 d+.4}$

B: plc, i4, $-x 2 d+.4, y 2 d+.4$ 


\section{We used the standard PT hohlraum to investigate the effect of different NIF focal spot sizes}

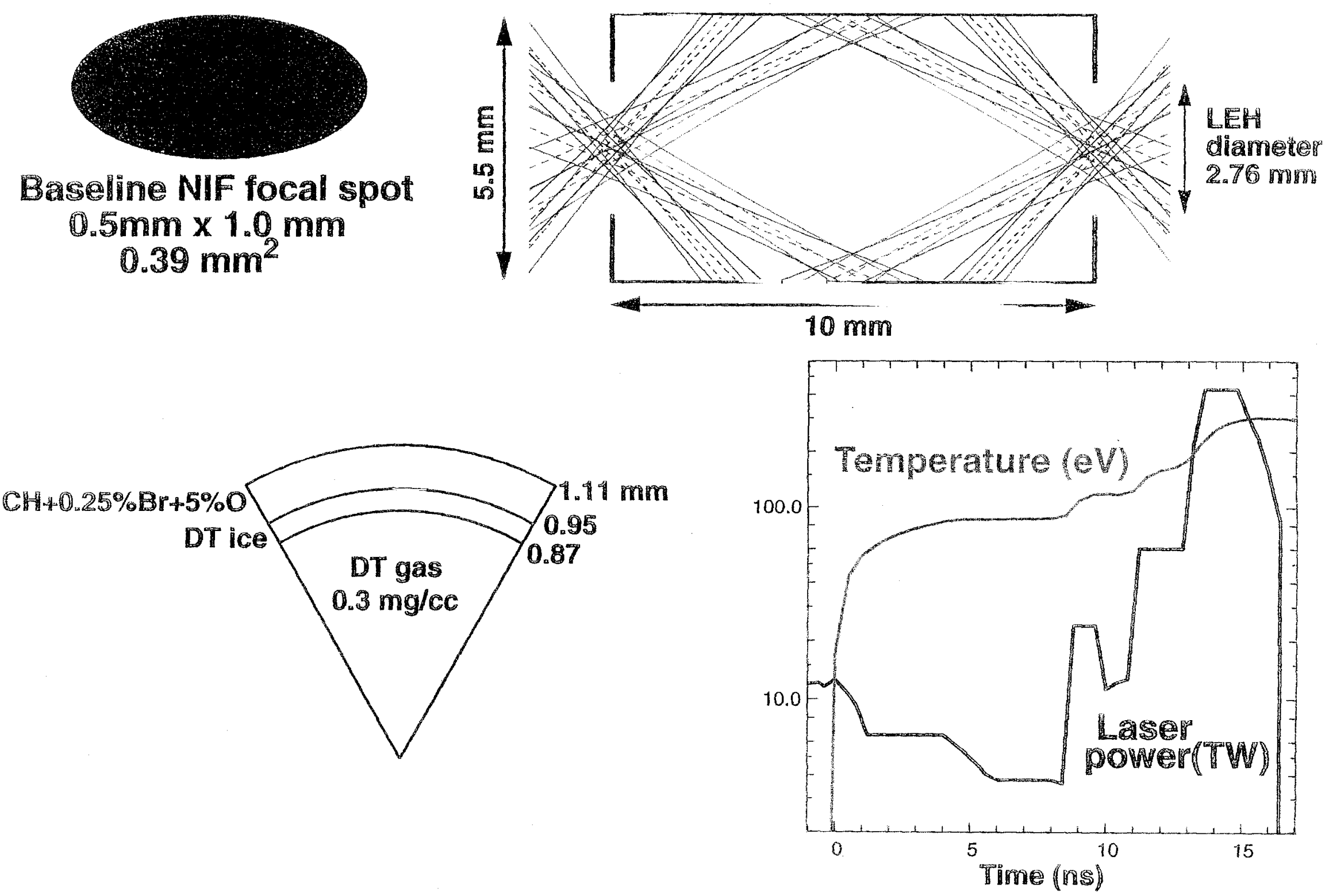




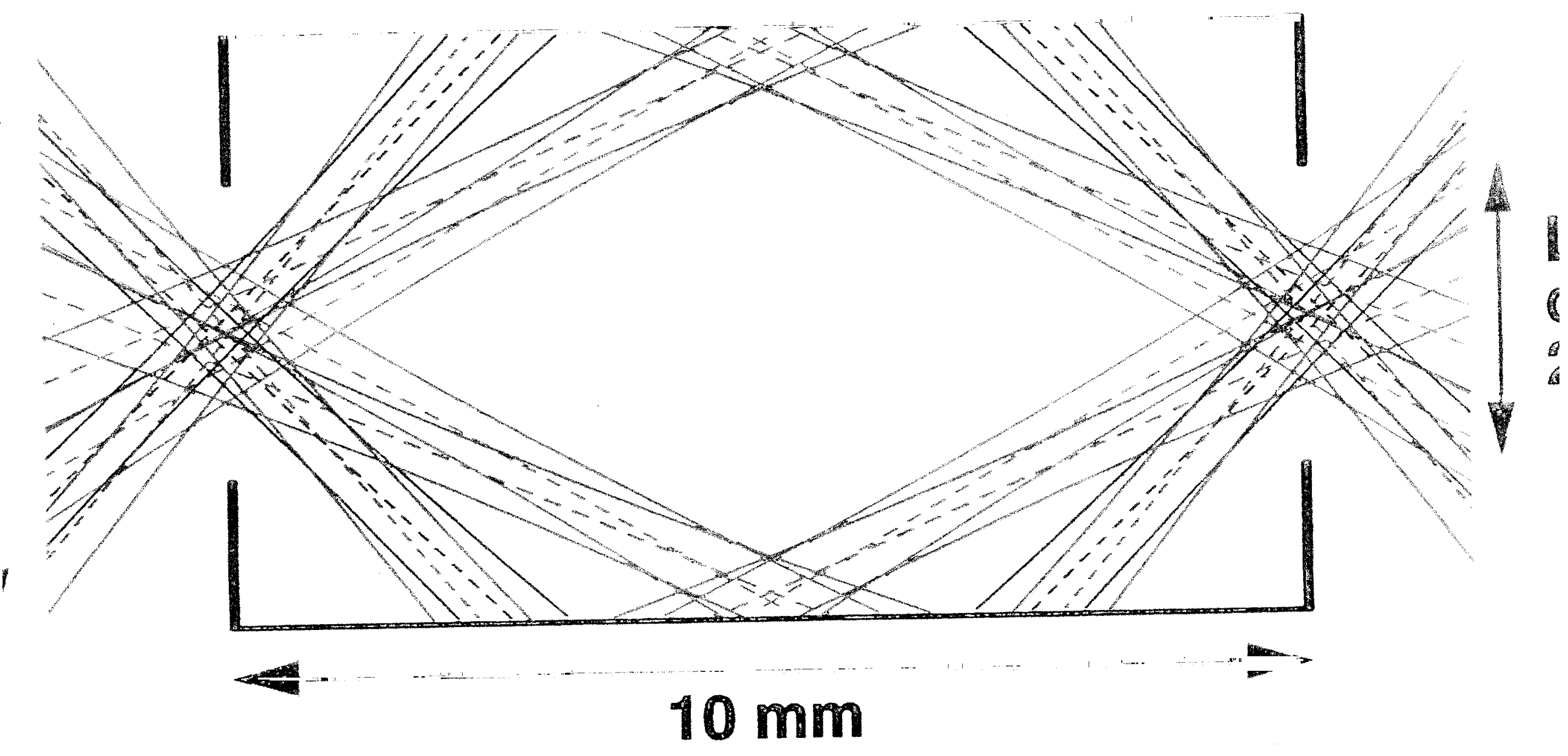

\section{$10 \mathrm{~mm}$}

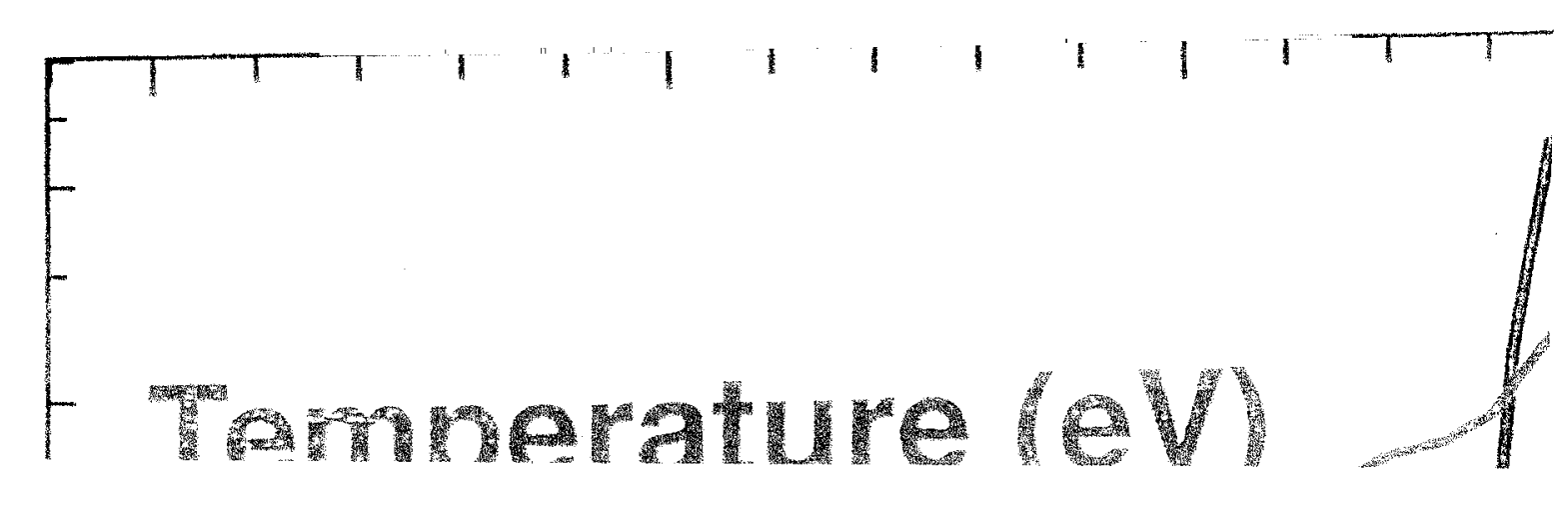


Energy inside radius vs radius

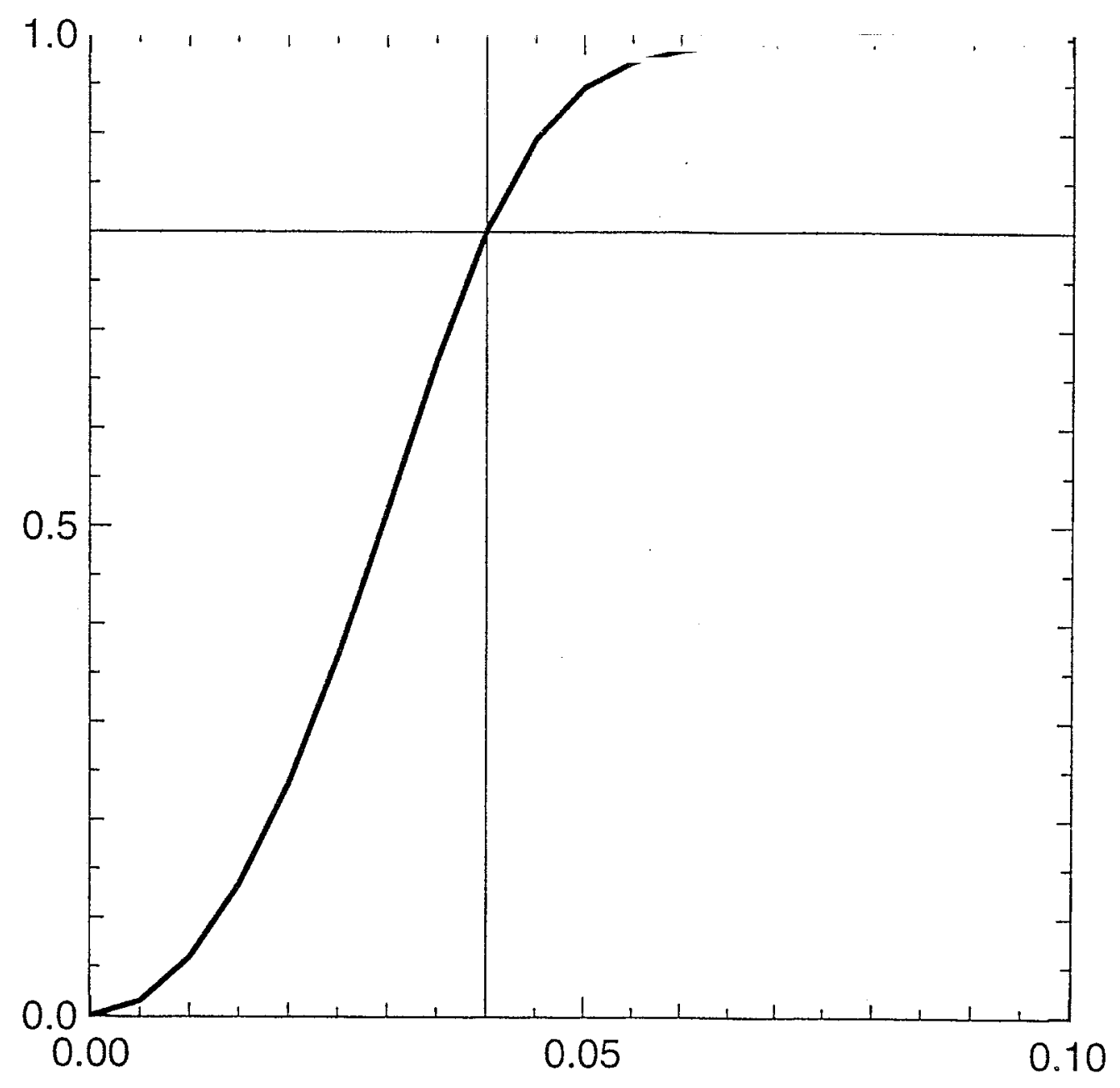

A: plg, e, d9

0.04

0.8 
Intensity vs Radius

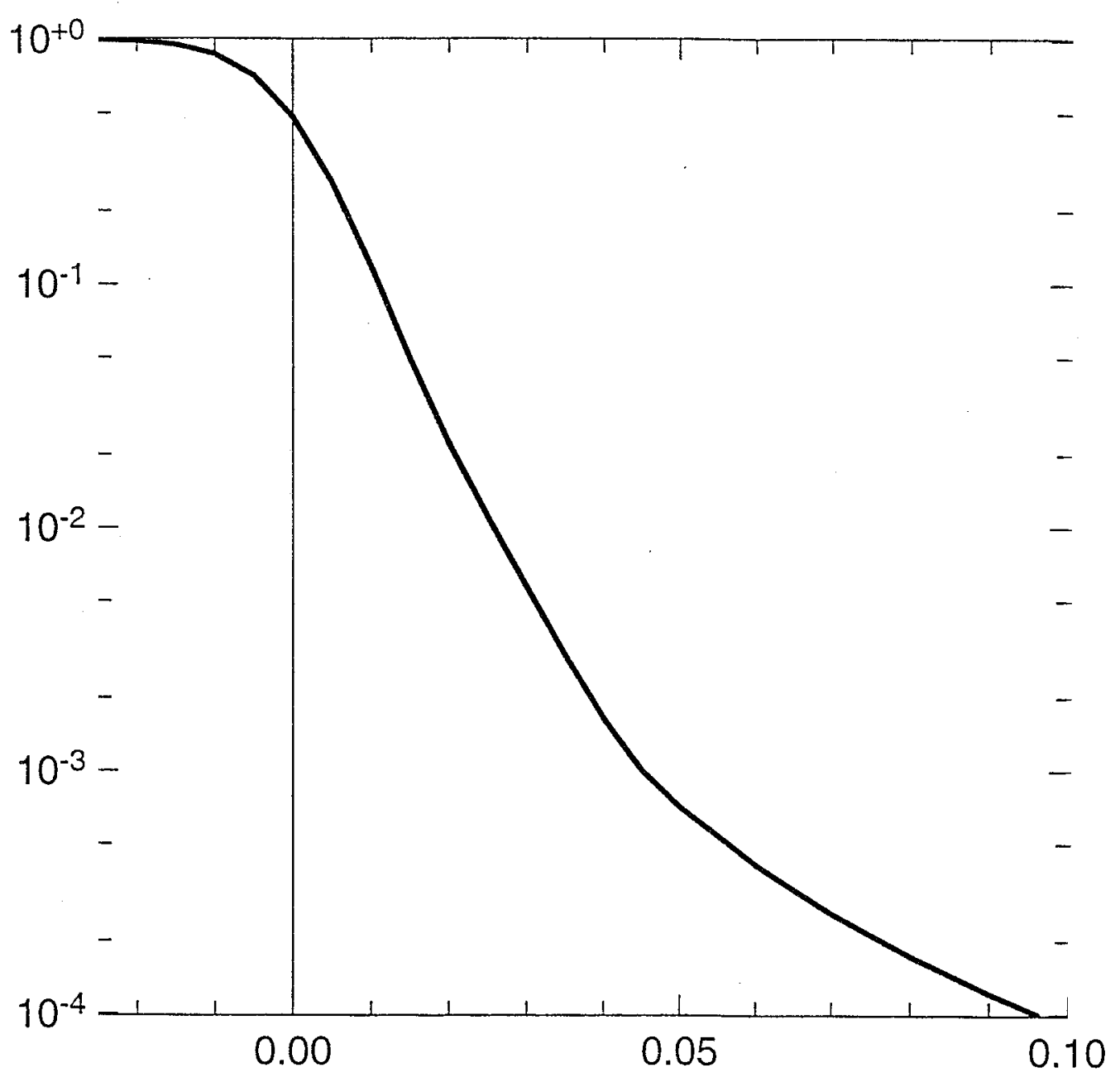

A: plg, inten8, d8 


\title{
Ignition hohlraums and NWET
}

\author{
Larry Suter
}


Intensity vs Radius

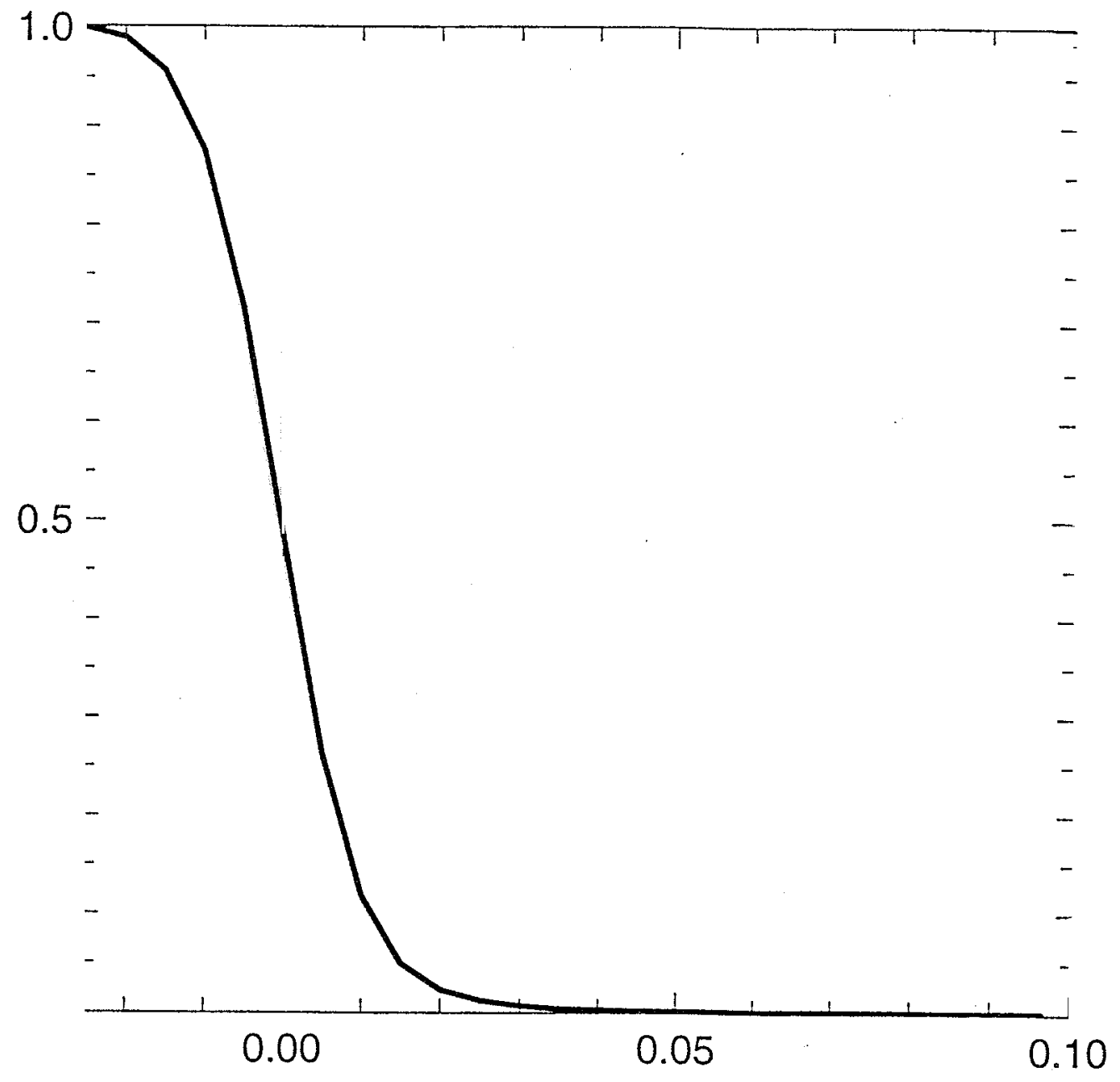

A: plg, inten $8, d 8$ 
High yield designs typically allow a bigger spot

Scale 1.0 NIF

(= scale 3.45 Nova)

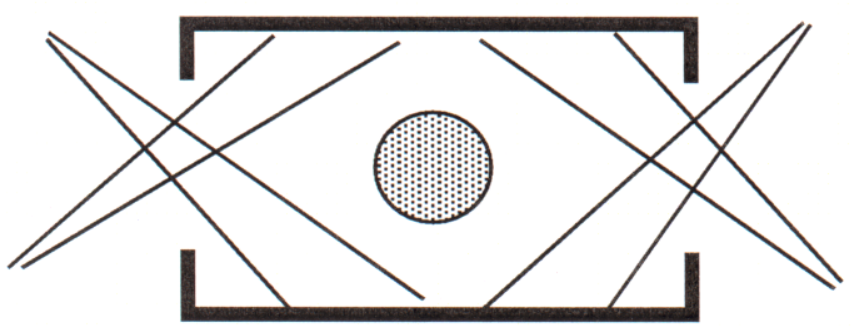

Point Design

$\mathrm{Tr}=\sim 300 \mathrm{eV}$

$\mathrm{Ecap}=150 \mathrm{~kJ}$

Elaser $450 \mathrm{TW} \times 3 \mathrm{~ns}=1.35 \mathrm{MJ}$

$$
\mathrm{Y} \sim 15 \mathrm{MJ}
$$

Scale 1.61 NIF

(5.55 Nova)

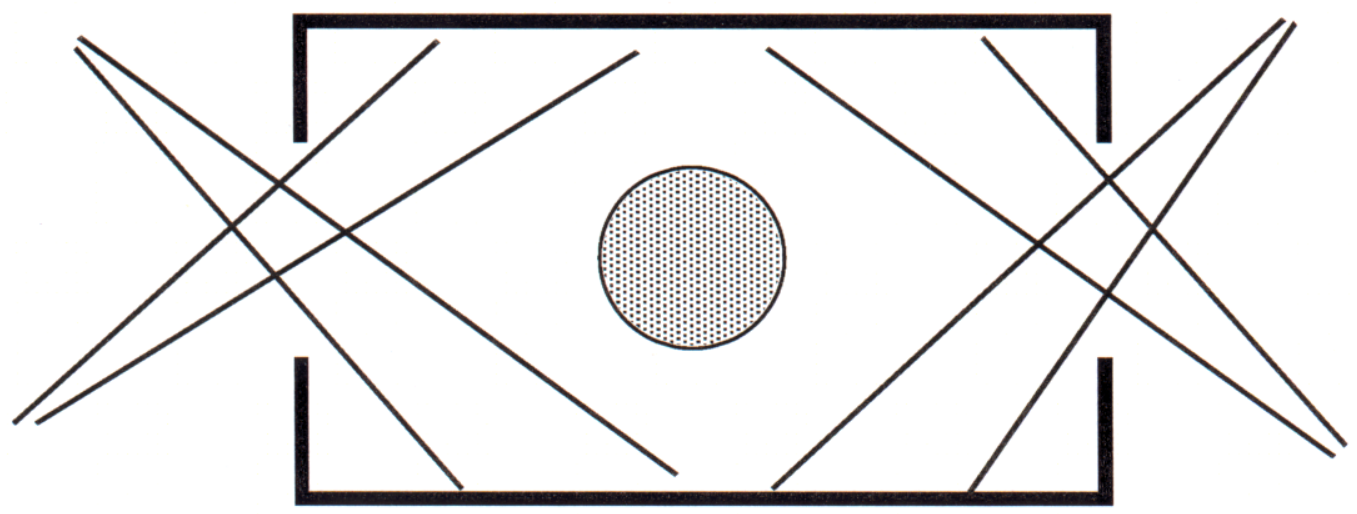

A 600kJ design

$\mathrm{Tr}=\sim 270 \mathrm{eV}$

Ecap $=600 \mathrm{~kJ}$

Elaser $\sim 300 \mathrm{TW} \times 8 \mathrm{~ns}=2.4 \mathrm{MJ}$

$\mathrm{Y} \sim 120 \mathrm{MJ}$

Even though such targets have a reduced fractional LEH area, the absolute LEH size is bigger 
Currently, we let the LEH dynamically close to an effective area $\sim 60 \%$ of the original hole's area

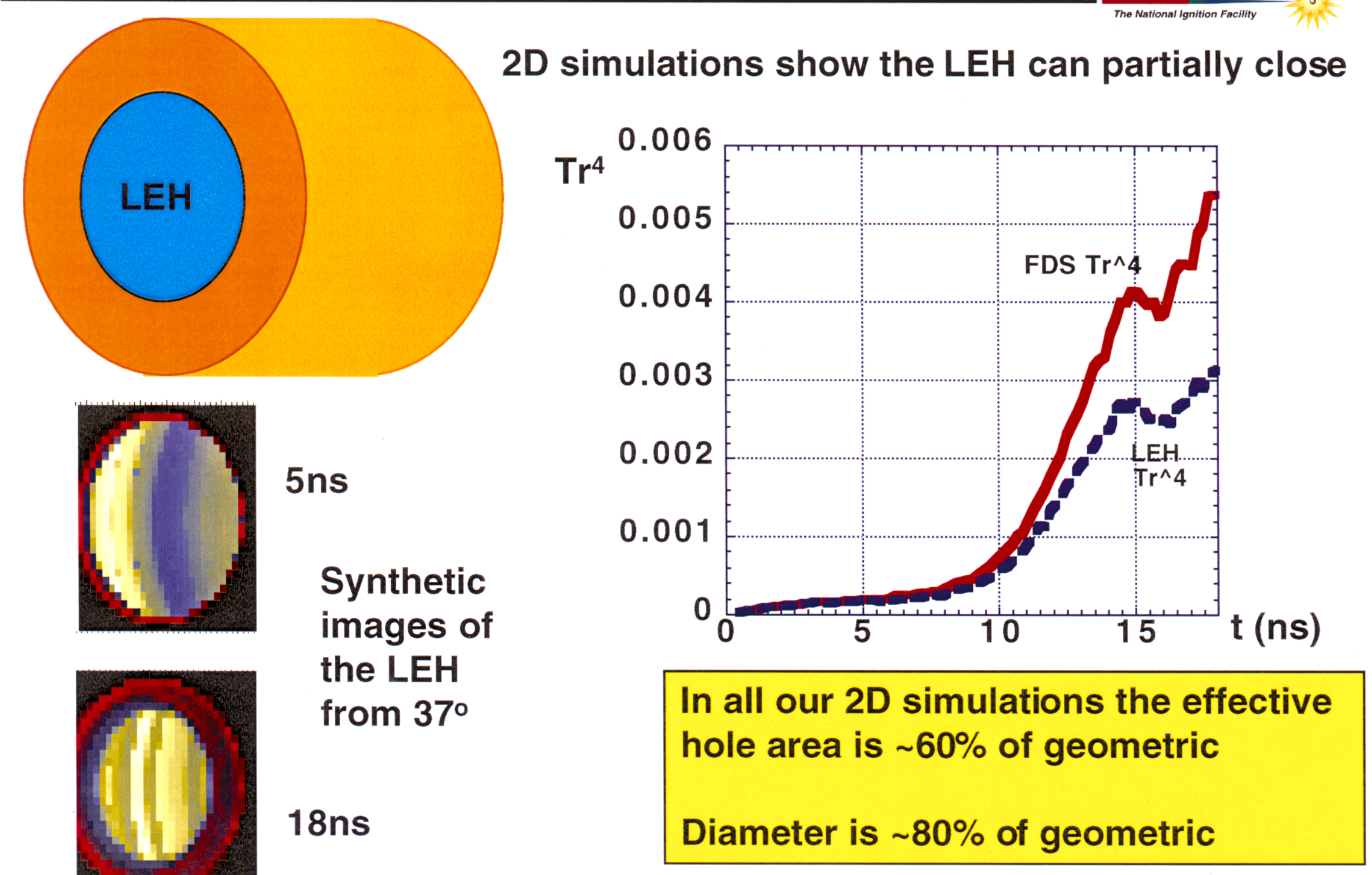


With 192 beams, high yield hohlraum size might range from scale 1.25 to 1.6

$$
1.0 \mathrm{NIF}=3.45 \text { Nova }
$$

$\begin{array}{cccccc}\operatorname{Tr} & \text { N beams } & \text { Rcc } & \text { limit } & \text { Ecap (kJ) } & \text { hohlraum scale } \\ 300 & 192 & 3.65 & \text { damage } & 350 & 1.26 \\ 300 & 192 & 3.28 & \text { damage } & 450 & 1.23 \\ 300 & 192 & 3.65 & \text { B-int } & 500 & 1.42 \\ 300 & 192 & 3.28 & \text { B-int } & 650 & 1.39 \\ & & & & & \\ 250 & 192 & 3.65 & \text { damage } & 600 & 1.61 \\ 250 & 192 & 3.28 & \text { damage } & 700 & 1.52 \\ 250 & 192 & 3.65 & \text { 1w energy } & 700 & 1.69 \\ 250 & 192 & 3.28 & \text { 1w energy } & 850 & 1.62\end{array}$


We can estimate an upper bound on spot size by assuming maximum $D_{\text {spot }} \sim 0.5 D_{\text {geometric }}$ of the LEH
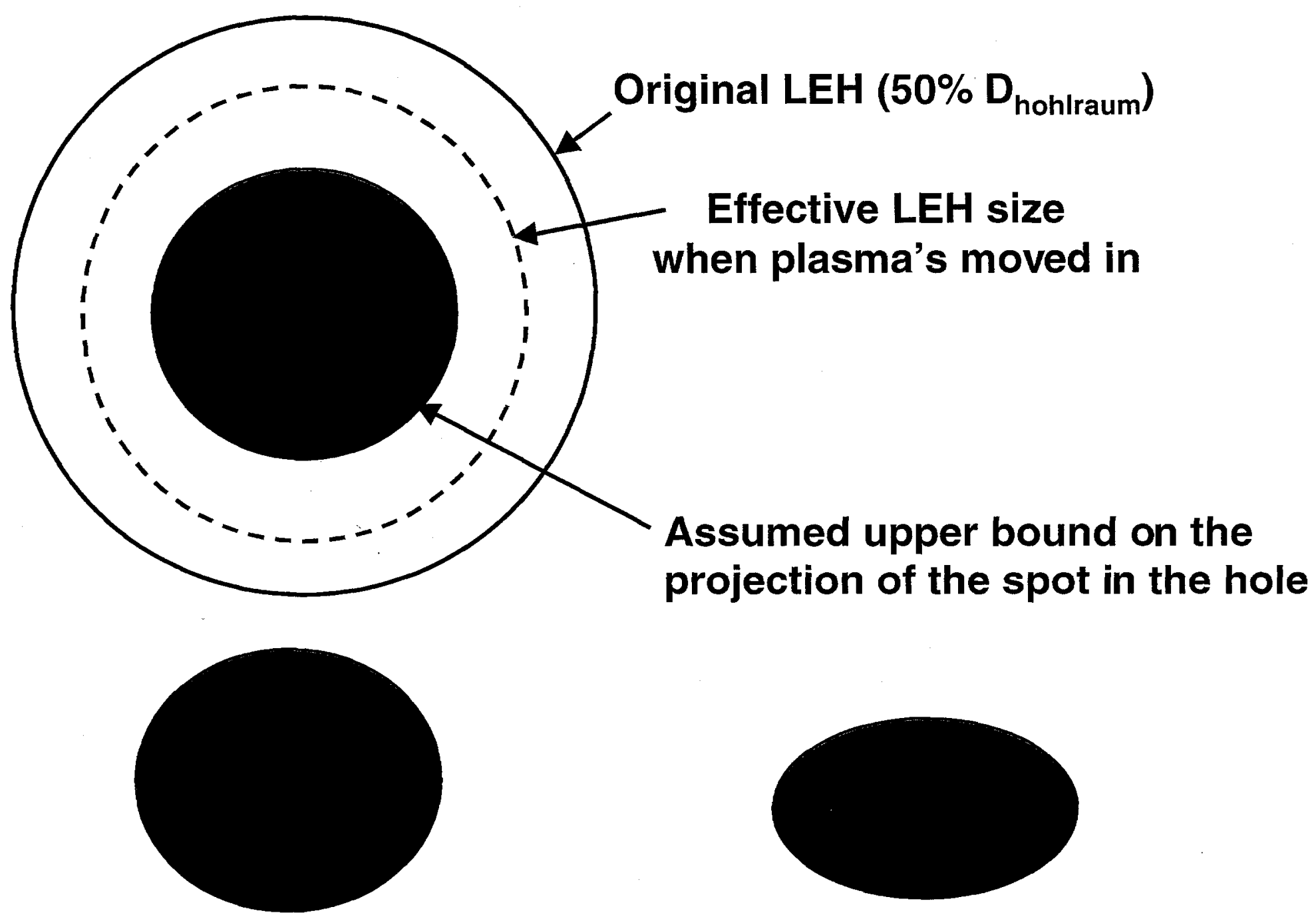

$23^{\circ}$ spot: 1 x .92

$50^{\circ}$ spot: 1 x .64 
This assumption leads to upper bounds on spot sizes $\sim 2 \mathrm{~mm}$ wide by $1-2 \mathrm{~mm}$ high

\begin{tabular}{|c|c|c|c|c|c|c|c|}
\hline $\operatorname{Tr}$ & Rcc & limit & Ecap (kJ) & scale & $\begin{array}{c}\text { LEH } \\
\text { diameter }\end{array}$ & $\begin{array}{c}\text { Max spot } \\
\text { width }\end{array}$ & $\begin{array}{l}\text { Max } 50 \text { deg } \\
\text { spot height }\end{array}$ \\
\hline 300 & 3.65 & damage & 350 & 1.26 & 0.35 & 0.17 & 0.11 \\
\hline 300 & 3.28 & damage & 450 & 1.23 & 0.34 & 0.17 & 0.11 \\
\hline 300 & 3.65 & B-int & 500 & 1.42 & 0.39 & 0.20 & 0.13 \\
\hline 300 & 3.28 & B-int & 650 & 1.39 & 0.38 & 0.19 & 0.12 \\
\hline 250 & 3.65 & damage & 600 & 1.61 & 0.44 & 0.22 & 0.14 \\
\hline 250 & 3.28 & damage & 700 & 1.52 & 0.42 & 0.21 & 0.14 \\
\hline 250 & 3.65 & 1 w energy & 700 & 1.69 & 0.47 & 0.23 & 0.15 \\
\hline 250 & 3.28 & 1 w energy & 850 & 1.62 & 0.45 & 0.22 & 0.14 \\
\hline
\end{tabular}


While smaller spots could be used, the relatively low intensities of bigger spots make them worth a struggle

NIF

The National Ignition Facility

$\begin{array}{cccccccc}\operatorname{Tr} & \text { Rcc } & \text { limit } & \text { Ecap (kJ) } & \text { scale } & \begin{array}{c}\text { Max Plaser } \\ \text { (TW) }\end{array} & \begin{array}{c}\text { Max outer I } \\ \text { (quad) }\end{array} & \begin{array}{c}\text { Max inner I } \\ \text { (quad) }\end{array} \\ 300 & 3.65 & \text { damage } & 350 & 1.26 & 540 & 7.4 \mathrm{E}+14 & 4.8 \mathrm{E}+14 \\ 300 & 3.28 & \text { damage } & 450 & 1.23 & 529 & 7.6 \mathrm{E}+14 & 4.9 \mathrm{E}+14 \\ 300 & 3.65 & \text { B-int } & 500 & 1.42 & 661 & 7.2 \mathrm{E}+14 & 4.6 \mathrm{E}+14 \\ 300 & 3.28 & \text { B-int } & 650 & 1.39 & 652 & 7.3 \mathrm{E}+14 & 4.7 \mathrm{E}+14 \\ & & & & & & & \\ 250 & 3.65 & \text { damage } & 600 & 1.61 & 380 & 3.2 \mathrm{E}+14 & 2.0 \mathrm{E}+14 \\ 250 & 3.28 & \text { damage } & 700 & 1.52 & 332 & 3.1 \mathrm{E}+14 & 2.0 \mathrm{E}+14 \\ 250 & 3.65 & \text { 1w energy } & 700 & 1.69 & 415 & 3.1 \mathrm{E}+14 & 2.0 \mathrm{E}+14 \\ 250 & 3.28 & \text { 1w energy } & 850 & 1.62 & 371 & 3.1 \mathrm{E}+14 & 2.0 \mathrm{E}+14\end{array}$




\section{Similar tables for 96 beams}

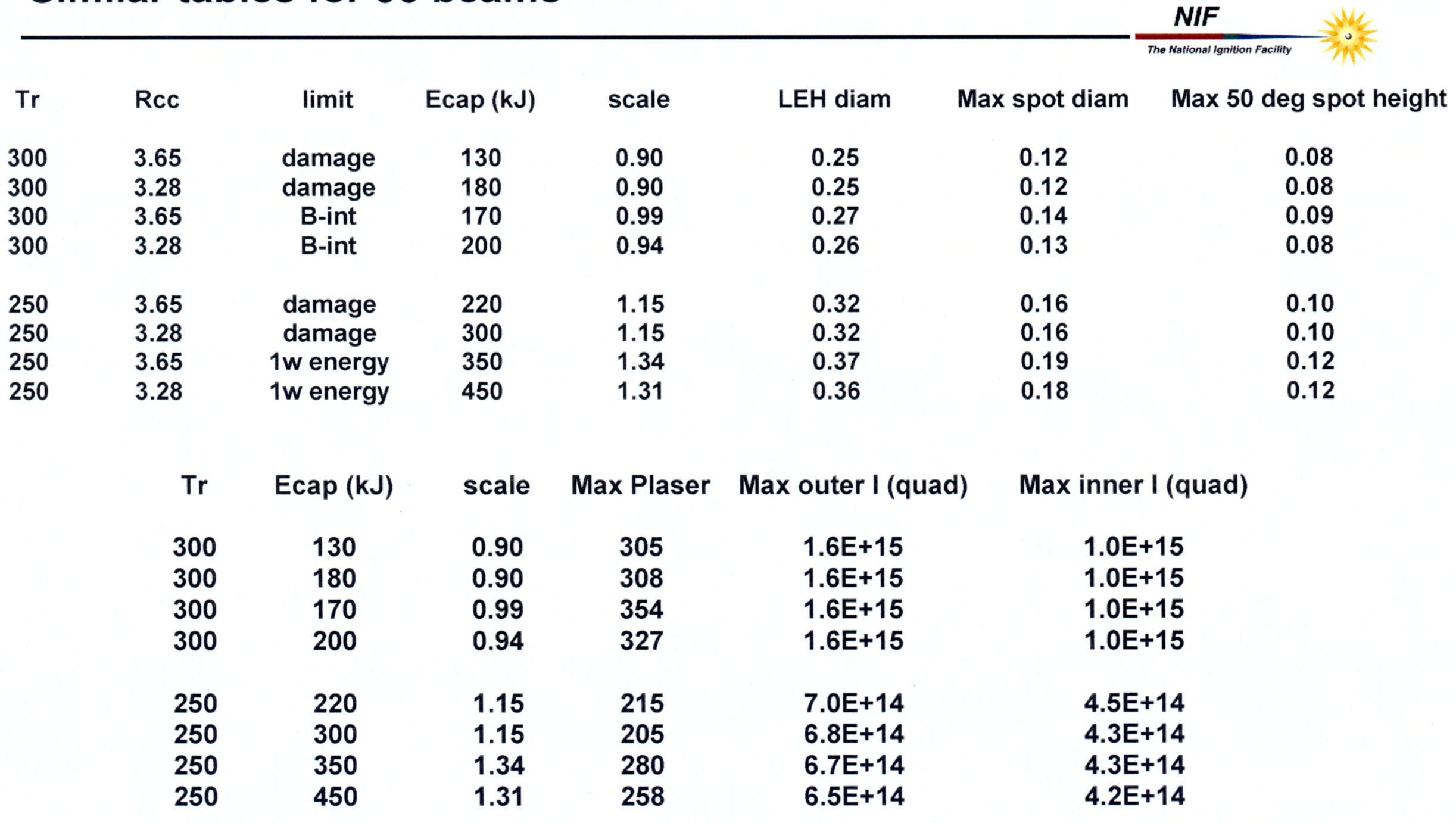

Half the beams doubles the single quad intensity 
A typical NIF/NWET source might be a $7.2 \mathrm{~mm}$ diameter sphere with a $4 \mathrm{~mm}$ LEH

Be sphere filled w/ 1atm Xe

It averages $25 \%>4 \mathrm{keV}$ production over $6 \mathrm{~ns}$

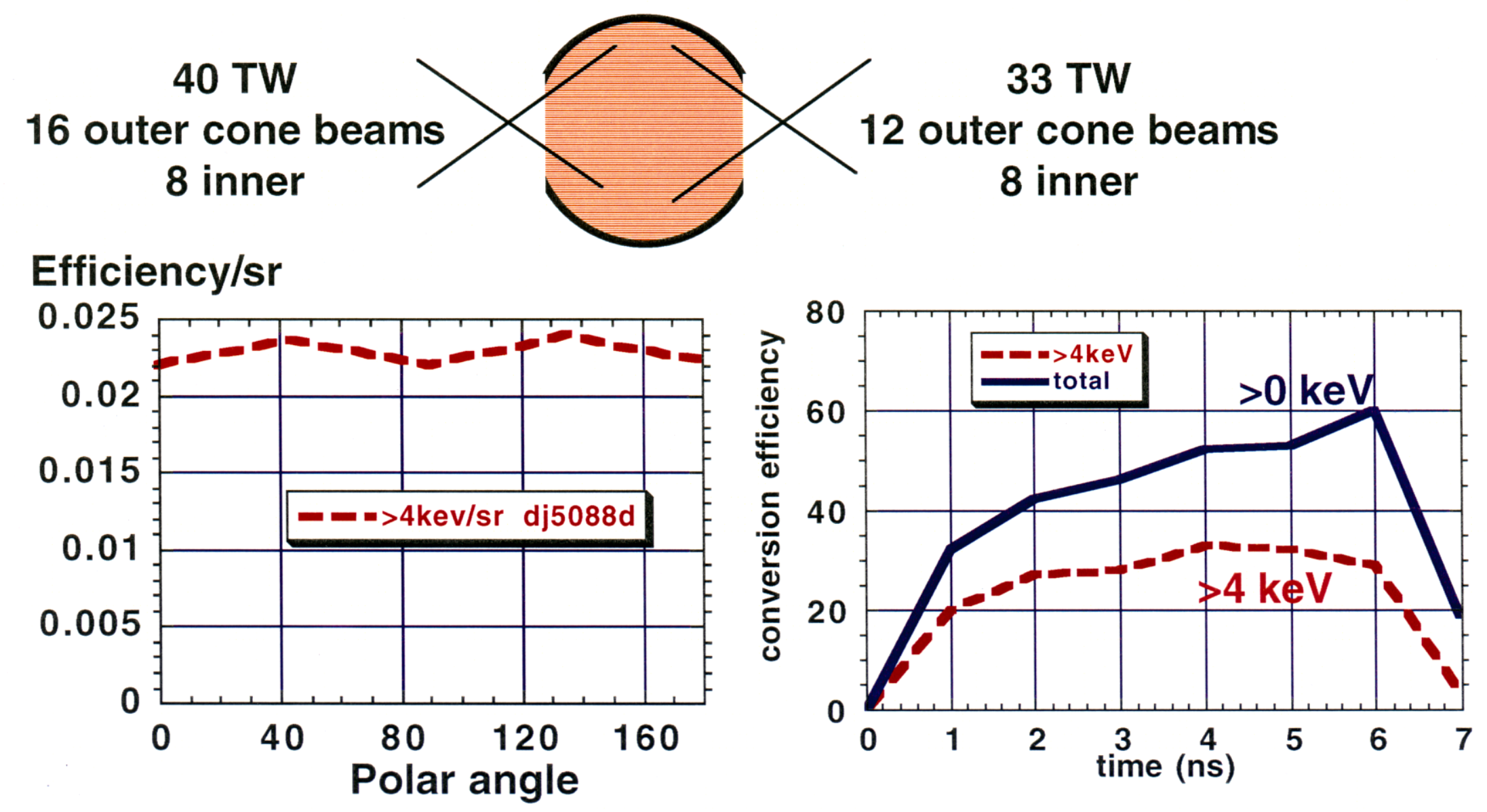


NWET spots which fill half the LEH

would be $\sim 2 \mathrm{~mm}$ by $1.3-2 \mathrm{~mm}$

NIF

The National Ignition Facility

\begin{tabular}{|cccccc|}
\hline D leh & D spot max & H spot 50 deg & P per beamlet & I inner & I outer \\
0.40 & 0.20 & 0.13 & 1.67 & $5.3 E+13$ & $8.3 E+13$ \\
\hline
\end{tabular}

For distributed sources with beamlets steered to different targets, the single beamlet intensity could be very low

These sources can use $44 / 48$ of NIF

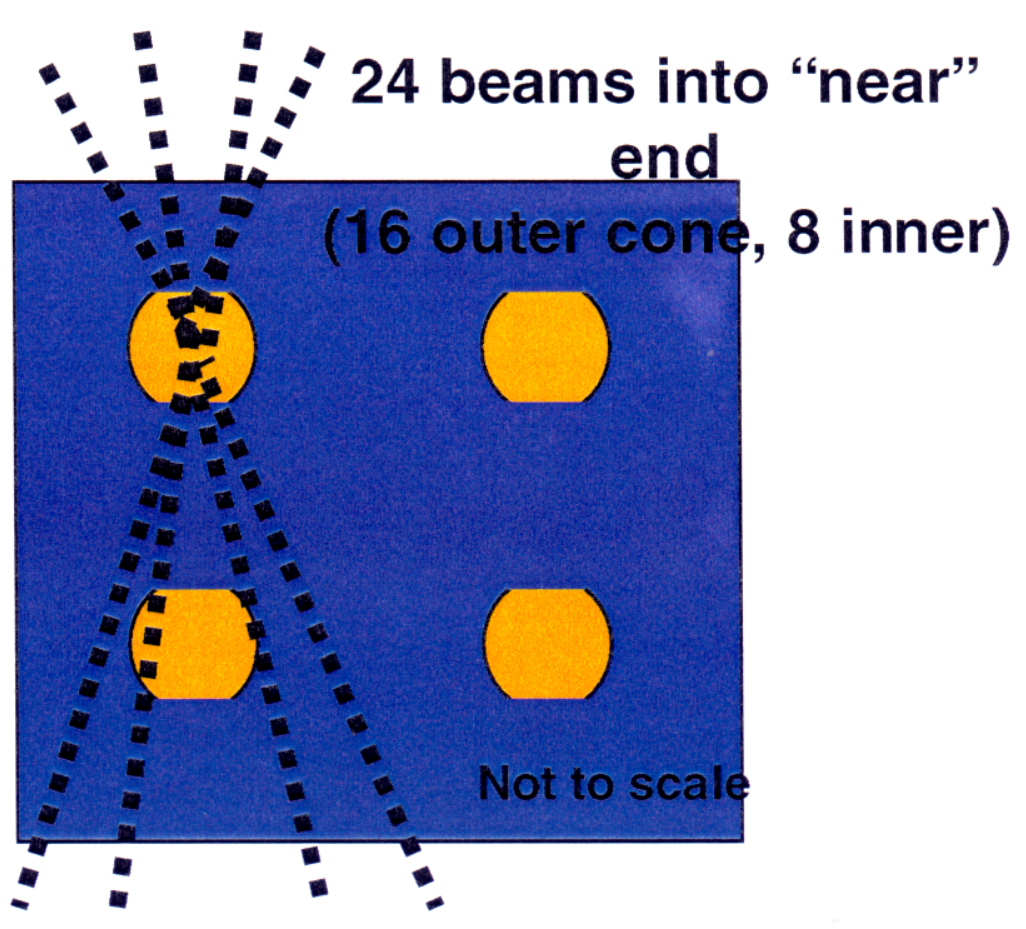




\title{
Planar hydro experiments
}

\author{
John Edwards
}


Planar hydro experiments need the largest spot sizes on NIF

192 beam scenario

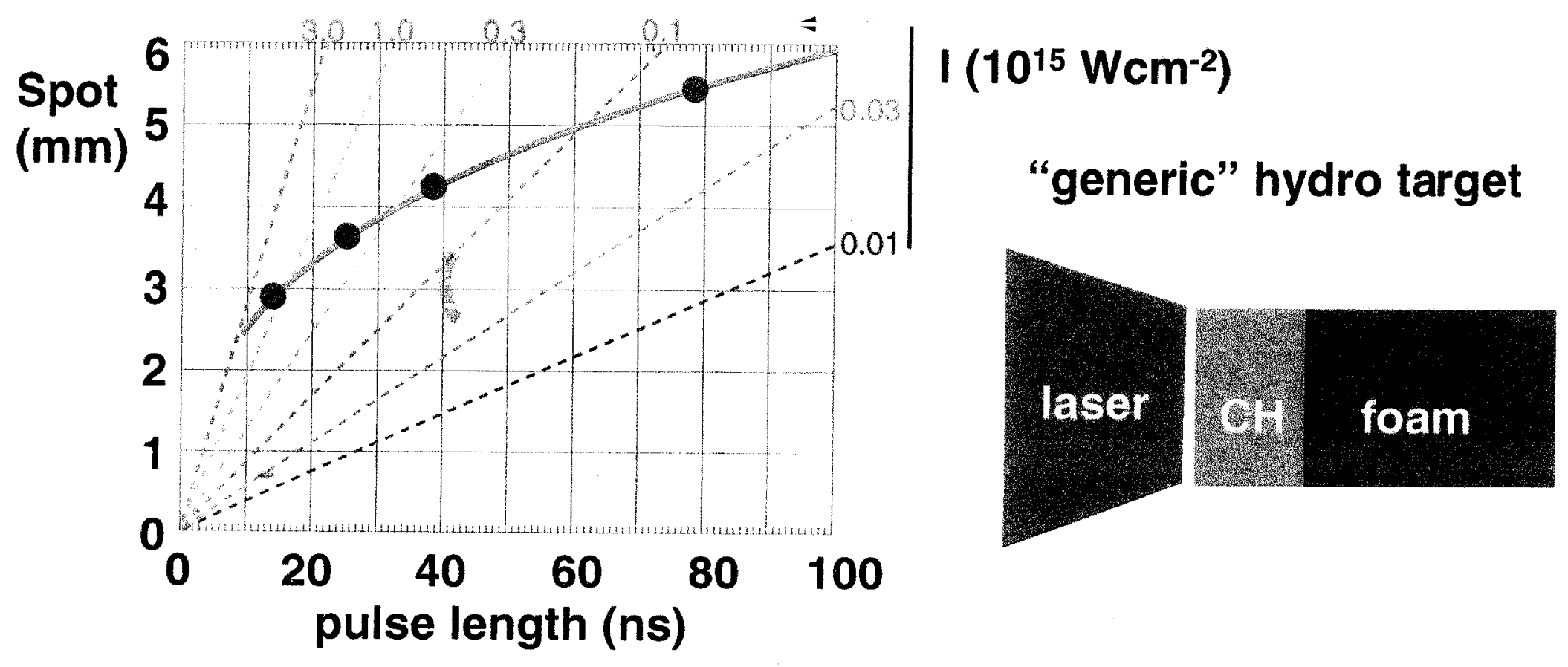

- For a fixed intensity on target spheres need $\sim 10 \%$ spots relative to planar equivalents

- And symmetry means we can't go to such long pulses for spheres 
We need large spatial scales to make worthwhile experiments
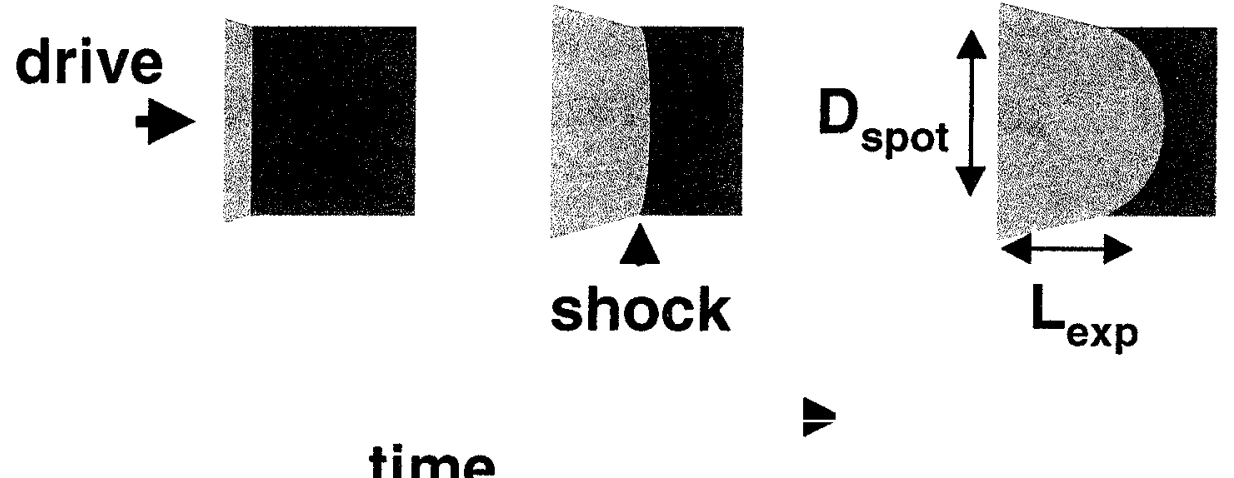

\section{Curvature eventually compromises the data}

time

- To "optimize" designs we make $L_{\text {exp }} \sim D_{\text {spot }}$

- For each intensity, pulse length combination there is a unique value of $D_{\text {spot }}$ (depending on target materials)

- This is defining target optimizations for NIF 
We often need to stack pulses

to make large experiments

This is because:

$$
L_{\text {exp }} \sim v_{\text {shock }} t \sim 1_{\text {las }}^{1 / 3} t \sim\left(\begin{array}{c}
E \\
D^{2} t
\end{array}\right)^{1 / 3} t
$$

But $L \sim D$ so that

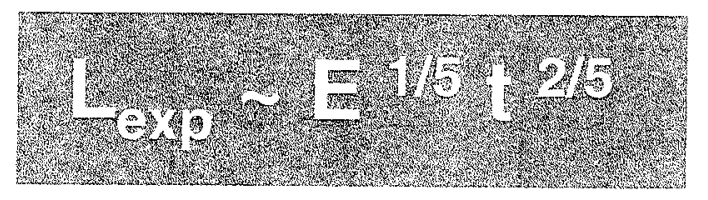

But to preserve illumination uniformity we require at least 4-fold symmetry

This means we can only get discrete pulse lengths (or does if a n. a ? )

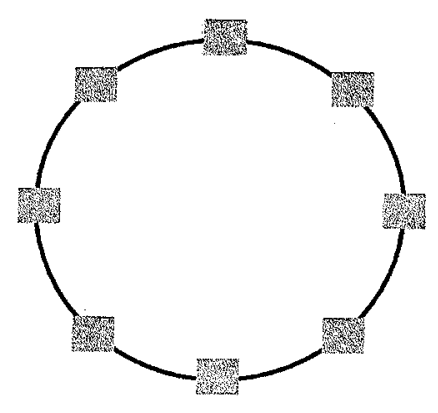


Laser spot size is less of an issue for indirect drive

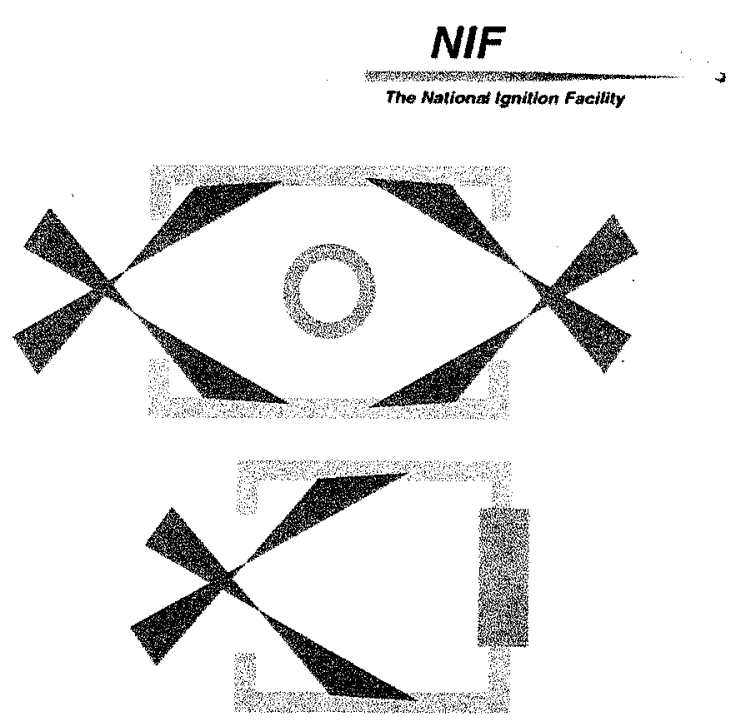

all in a hohlraum constantly filling up with plasma

- Again, hydro experiments need the largest hohlraums up to scale 3 NIF (or more), \& longest pulses

- Thus spots could be up to $\sim$ few $X$ ignition spots

- Although optimum spots will be determined thru expt \& modeling they should fall within the DD envelope 
We are doing simulations and Omega

experiments to help resolve the important issues

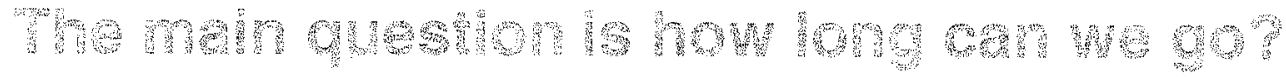

The target design issues are:

Direct drive

- Planarity

- Laser-target coupling vs pulse length \& beam angles

Indirect drive

What are limiting factors?

- Drive-target coupling

This work will help define more precise target designs for NIF 


\section{Improvement of the NIF focal spot by diffractive correction}

\section{NIF}

The National Ignition Facility

Joshua E. Rothenberg

WBS-1 Focal Spot Meeting

February 16, 2000 


\section{Diffractive Optics can be used to condition the basic NIF focal spot to meet the requirements of the ICF mission}

- a KPP can be used to form an elliptical focal spot which optimally fills the LEH such that the peak intensity is reduced to a tolerable level

- a B-integral phase corrector (BIPC) can be used to reduce the focal spot wings (which impinge on the LEH and its associated plasma blow off) originating from whole beam self-focusing. However, the remaining wings may still be too large.

- In conjunction with the BIPC, an aberration corrector in the laser front end can be used to reduce the remaining wings such that the resultant focal spot meets the initial target specifications at the LEH.

- SSD can be used to reduce plasma instabilities resulting from speckle "hot spots" -- at the cost of smearing out the focal spot wings 
We have investigated other phase correction schemes which are not currently part of the baseline laser $_{\text {NIF }}$

- B-integral corrector plate (part of KPP?)

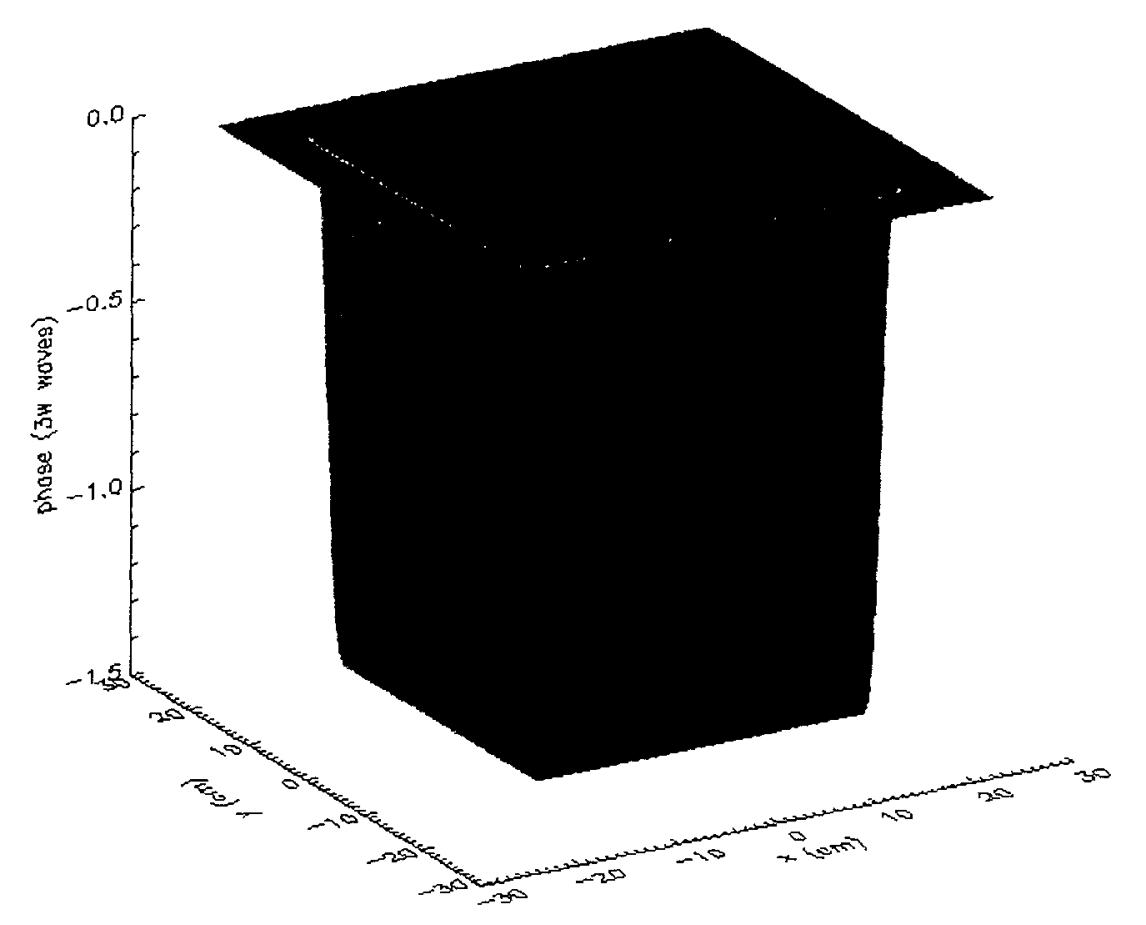

- passive/pump-induced aberrations corrector plate (in front end?)

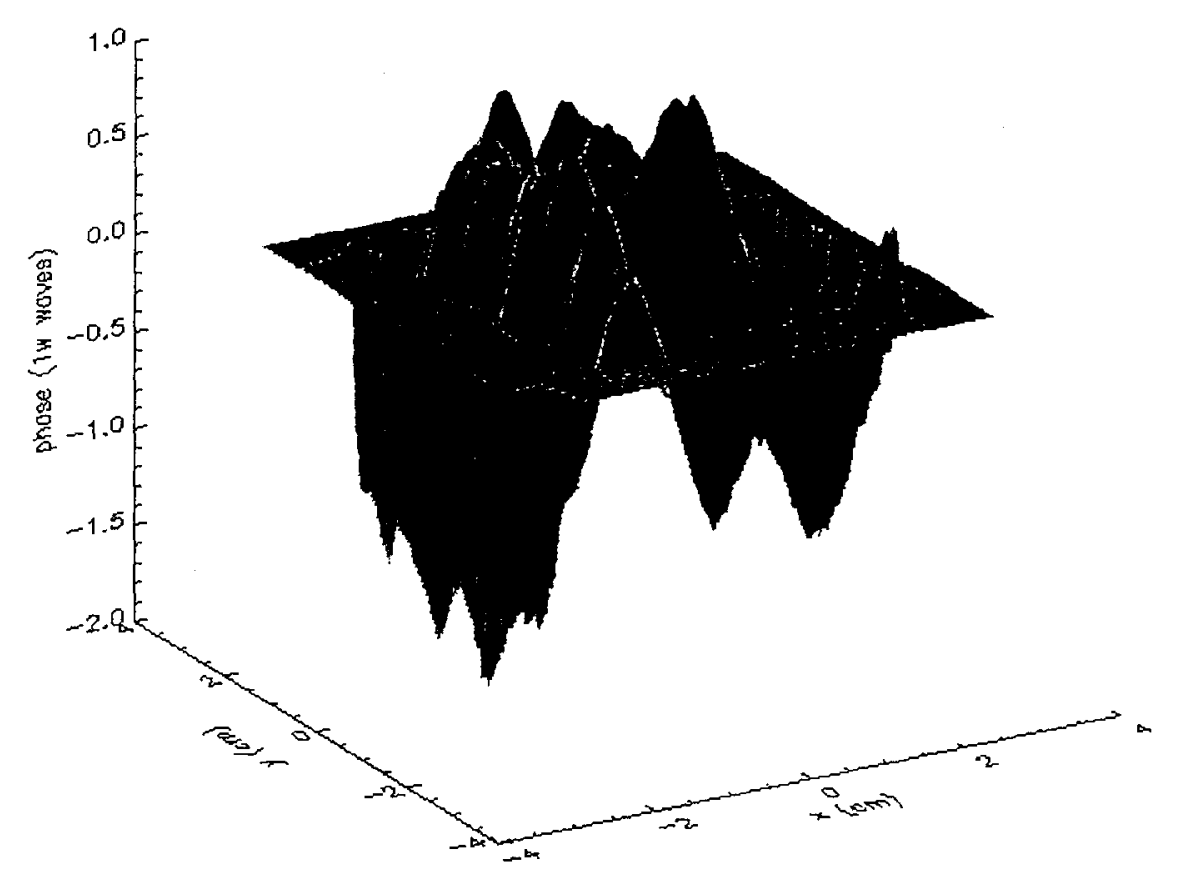




\section{$3 \omega$ spot with various types of correction}

\section{NIF}

no correction $\quad$ BIPC only ab. corr. only BIPC $+a b$. corr.

\section{foot of pulse}

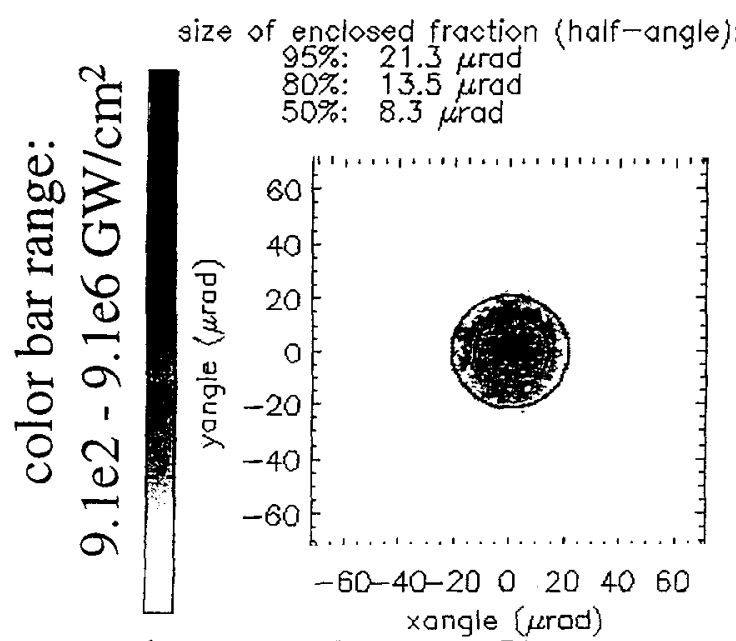

\section{peak of pulse}

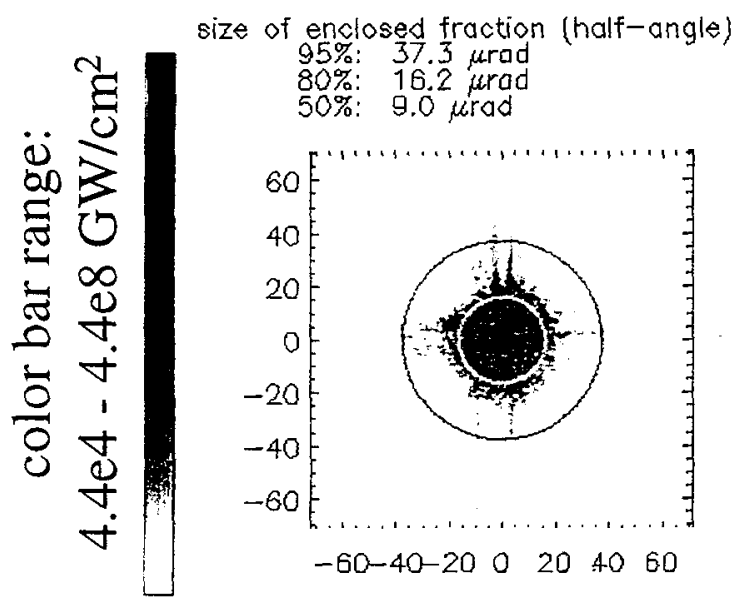

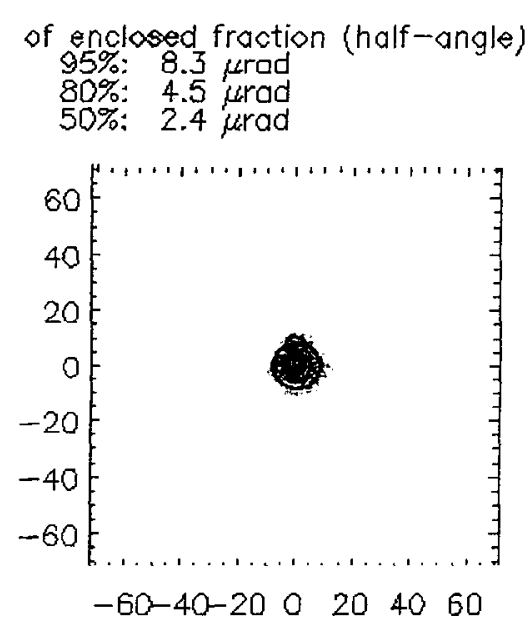

$-60-40-20 \quad 0 \quad 20 \quad 4060$ of enclosed fraction (half-angle): 95\%: $11.1 \mu \mathrm{rad}$ 50\%: 2.0 prad

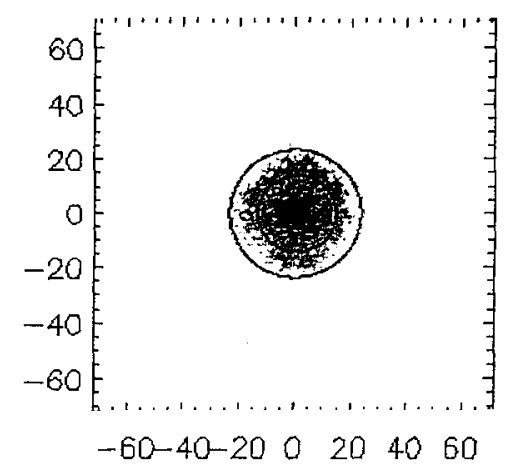

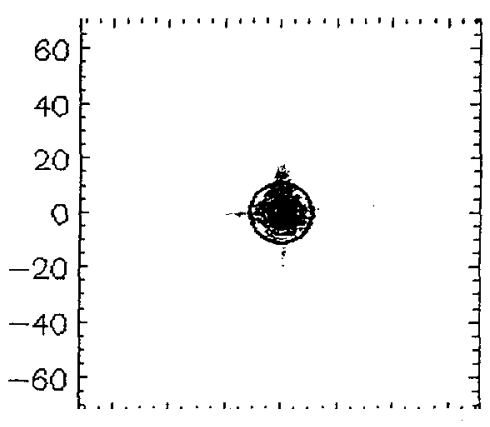

$-60-40-20 \quad 0 \quad 20 \quad 4060$

size of enclosed fraction (half-angle.): size of enclosed fraction (half-angle)ze of enclosed fraction (half-angle

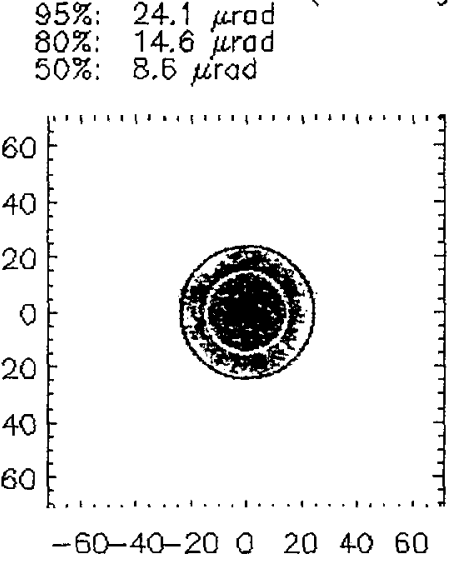
85\%: $34.8 \mu \mathrm{rad}$ 50\%: $2.9 \mu \mathrm{rad}$ 95\%: 14.5 mrad
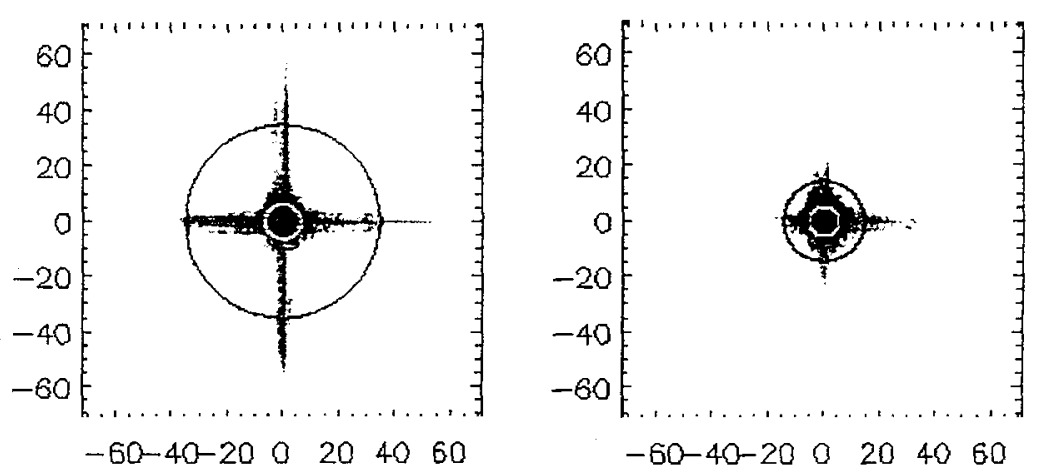

enclosing circles at $80 \%$ and $95 \%$ 
Phase correction of whole beam self-focusing with the $B I P C$ can reduce the wings, especially when the $1 \omega$ optical aberrations at short spatial scale are reduced

Blue curves at peak (2.5 TW) and brown curves in foot (50 GW)

With complete aberration correction

Without aberration correction

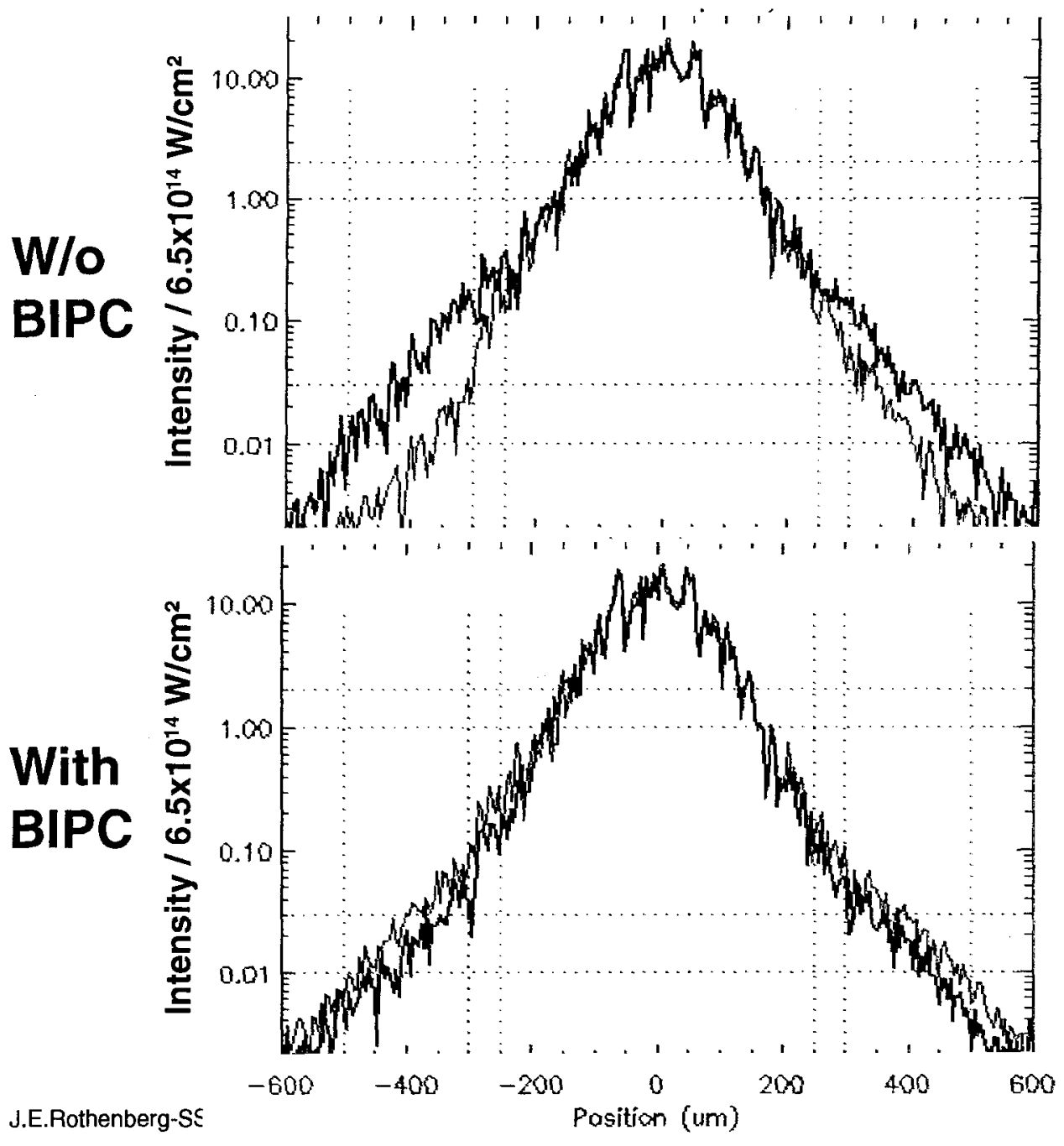

(e.g. by a phase plate in the front end)
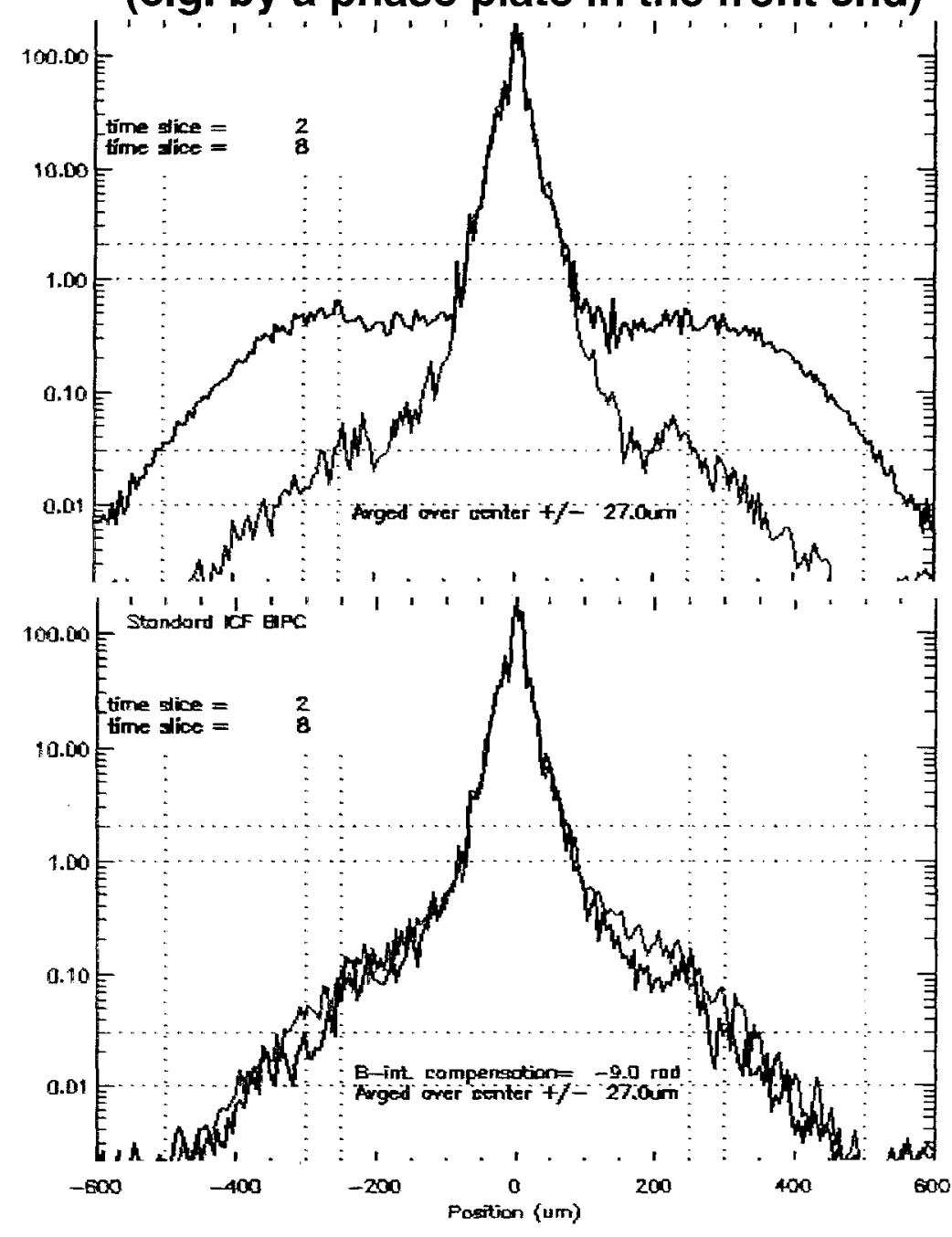


\section{MUCH better focal spots are possible using a static phase corrector plate $(80 \%$ energy Diam. $250 \mu \mathrm{m} \rightarrow 100 \mu \mathrm{m})$

with B-intergral phase and aberration corrector (green)

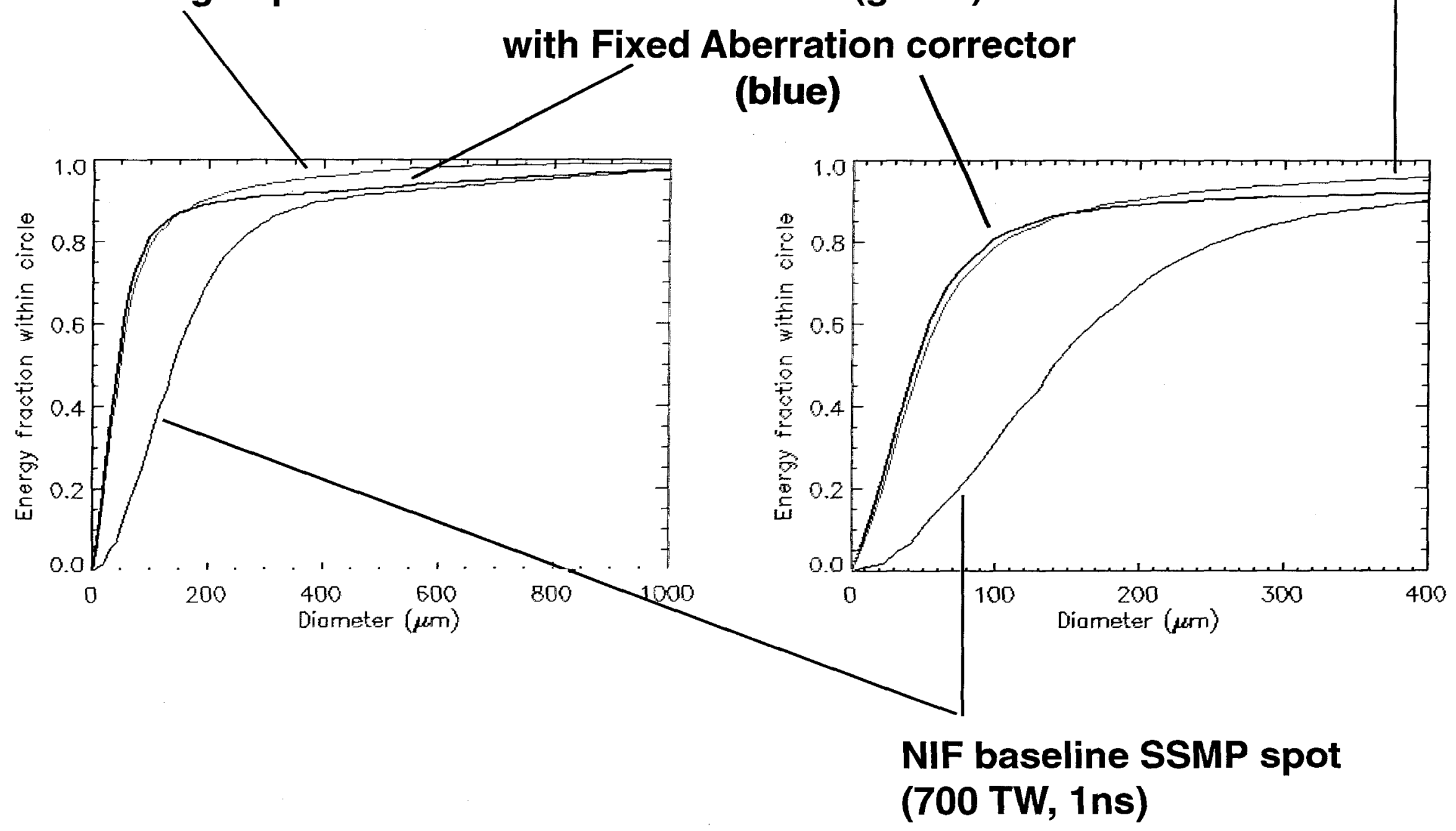




\section{Calculated energy fractions as a function of diameter for baseline and aberration corrected NIF spots}

\begin{tabular}{|c|c|}
\hline Diameter & Energy fraction \\
\hline $\begin{array}{c}0.00000 \\
10.8108\end{array}$ & $\begin{array}{c}0.00000 \\
0.0987434\end{array}$ \\
\hline 21.6216 & 0.227954 \\
\hline 32.4324 & 0.368667 \\
\hline 43.2432 & 0.491662 \\
\hline 54.0540 & 0.607971 \\
\hline 64.8648 & 0.686555 \\
\hline 75.6756 & 0.735704 \\
\hline 86.4864 & 0.772260 \\
\hline 97.2972 & 0.808491 \\
\hline 108.108 & 0.828530 \\
\hline 118.919 & 0.842351 \\
\hline 129.730 & 0.855544 \\
\hline 140.540 & 0.866747 \\
\hline 151.351 & 0.873223 \\
\hline 162.162 & 0.878551 \\
\hline 172.973 & 0.883215 \\
\hline 183.784 & 0.887425 \\
\hline 194.594 & 0.890572 \\
\hline 205.405 & 0.894175 \\
\hline 216.216 & 0.897073 \\
\hline
\end{tabular}

without correction

\begin{tabular}{r|l} 
Diameter & Energy fraction \\
& \\
0.00000 & 0.00000 \\
10.8108 & 0.0117182 \\
21.6216 & 0.0208129 \\
32.4324 & 0.0528235 \\
43.2432 & 0.0727015 \\
54.0540 & 0.123211 \\
64.8648 & 0.165715 \\
75.6756 & 0.202568 \\
86.4864 & 0.248713 \\
97.2972 & 0.302193 \\
108.108 & 0.352430 \\
118.919 & 0.401881 \\
129.730 & 0.439810 \\
140.540 & 0.499434 \\
151.351 & 0.543560 \\
162.162 & 0.586622 \\
172.973 & 0.620531 \\
183.784 & 0.648846 \\
194.594 & 0.682651 \\
205.405 & 0.711537 \\
216.216 & 0.737749 \\
227.027 & 0.757952 \\
237.838 & 0.778337 \\
248.648 & 0.794796 \\
259.459 & 0.808221 \\
270.270 & 0.823035 \\
281.081 & 0.834496 \\
291.892 & 0.844571 \\
302.702 & 0.853051 \\
313.513 & 0.861217 \\
324.324 & 0.868287 \\
& \\
\hline &
\end{tabular}

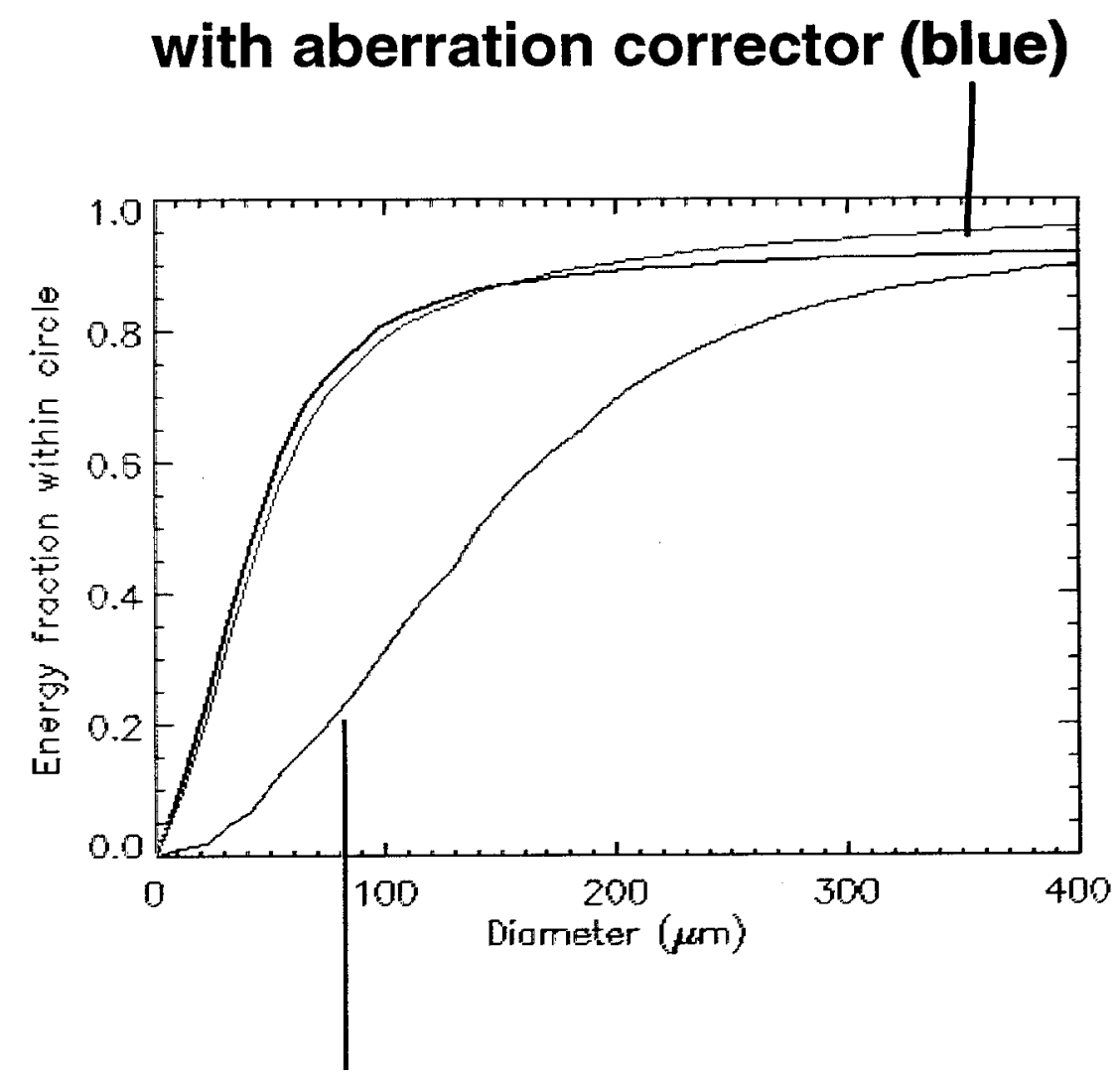

NIF baseline SSMP spot (700 TW, 1ns) 